\title{
Indicadores de calidad aplicables al análisis, evaluación y comparación de opacs
}

\author{
Por $\mathbf{M}^{\mathbf{a}}$ Victoria Játiva Miralles
}

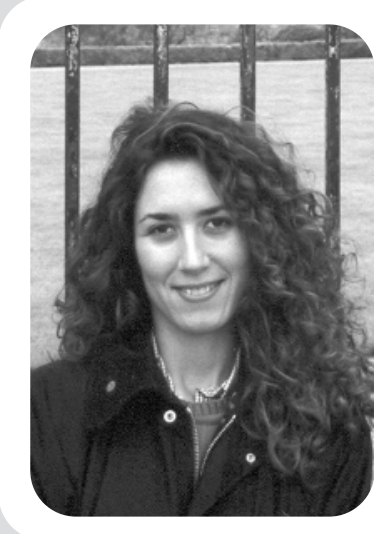

Mำ Victoria Játiva Miralles, diplomada en biblioteconomía y documentación y licenciada en documentación por la Universidad de Murcia. Desde 1997 es bibliotecaria en el Sibid (Servei d'Informació Bibliogràfica i Documental) de la Universidad de Alicante. Actualmente trabaja como responsable de la biblioteca de Filosofía y Letras-Trabajo Social de dicha universidad.

\begin{abstract}
Resumen: Se proponen unos indicadores de medición y evaluación de la calidad de los opacs desde el punto de vista del almacenamiento y estructura de la información, así como desde el punto de vista de la facilidad de uso y la adecuación a las necesidades del usuario. Se analizan algunos interfaces web implementados en bibliotecas españolas con los sistemas: Unicorn (WebCat, iLink), Innopac (Fama), Vtls, Absys.

Palabras clave: Evaluación de opacs, Indicadores de rendimiento, Interfaces, Calidad de opacs en entorno web.

Title: Quality indicators for the analysis, evaluation and comparison of opacs
\end{abstract}

Abstract: This article proposes a range of indicators for measuring and evaluating opac quality, with regards to aspects such as the storage and structure of information or the simplicity and suitability to user needs. An analysis is provided of several of the web interfaces implemented in Spanish libraries, such as Unicorn (WebCat, iLink), Innopac (Fama), Vtls and Absys.

Keywords: Opac evaluation, Measurement indicators, Interfaces, Quality of web-based opacs.

Játiva Miralles, $\mathbf{M}^{a}$ Victoria. “Indicadores de calidad aplicables al análisis, evaluación y comparación de opacs”. En: El profesional de la información, 2004, enero-diciembre, v. 13, n. 1, pp. 28-46.

\section{Importancia de la calidad y la evaluación aplicadas al análisis de opacs}

La finalidad de este trabajo es hacer una propuesta de indicadores para medir y evaluar la calidad de distintos opacs implementados en bibliotecas universitarias españolas. Como señala Pinto (1994) "este nuevo paradigma de la calidad, aplicado al campo documental, contribuirá a la mejora de productos y, consiguientemente, de los servicios documentales". Cuando se habla de productos documentales es necesario tener en cuenta la distinción que indica la misma autora entre "calidad descriptiva (se vincula a la fidelidad al documento original (calidad intrínseca) y la calidad recuperativa (dependerá de factores externos al propio documento relacionados con su búsqueda y recuperación)". $\mathrm{Y}$ es que, en definitiva, añade "la calidad en el almacenamiento es un paso previo para la calidad en la búsqueda".

La intención del estudio es evaluar la implementación que de las distintas herramientas de software hacen diferentes universidades españolas, las cuales adoptan opciones o características que no necesaria- mente vienen predefinidas inicialmente por el producto elegido. Por lo tanto, el enfoque del trabajo es, básicamente, el del análisis y valoración de la adaptación y los ajustes materializados en las distintas bibliotecas universitarias, y no las funcionalidades completas que ofrecen Absys, iLink, Innopac, Vtls o Webcat.

Resulta necesario aclarar que los creadores de software son los encargados de elaborar las aplicaciones con múltiples características y funcionalidades, correspondiéndole a las bibliotecas y centros de información la elección de qué opciones quieren habilitar y disponer en sus catálogos.

Hay que precisar que en el opac de cualquier software casi todo es parametrizable (los formatos de visualización, las opciones de búsqueda u operadores disponibles, el tamaño y aspecto de los botones, tipos de letra y otros elementos gráficos que influyen sobre el tamaño de la pantalla, márgenes, etc.) y que, frecuentemente, lo que se visualiza en los catálogos de las bibliotecas universitarias refleja las opciones, gustos y preferencias de ese centro, no las únicas posibilidades de cada programa. De ahí se deriva la importancia del trabajo de los bibliotecarios a la hora de seleccionar las 


\begin{tabular}{|l|}
\multicolumn{1}{|c|}{ Principales mejoras de los opacs } \\
\hline - Uso de entornos gráficos: ventanas, iconos, frames, logos, etc. \\
\hline - Comunicación del usuario con la biblioteca: desideratas-e, sugerencias, consultas, horarios, \\
renovaciones de préstamo, reservas de documentos, etc. \\
\hline - Diseño atractivo, sencillo, cómodo y fácil de usar. \\
\hline - Información "en tiempo real" de la localización de documentos. \\
\hline - Diversidad de campos de recuperación y herramientas de búsquedas más potentes. \\
\hline - Uso del hipertexto y de los hiperenlaces. \\
\hline - Opac multi-idioma. \\
\hline - Aumento de las posibilidades de presentación de resultados. \\
\hline - Acceso a otros catálogos mediante el protocolo Z39.50. \\
\hline - Uso del campo 856 del formato marc. \\
\hline
\end{tabular}

\begin{tabular}{|c|}
\hline Deficiencias de los opac \\
\hline - Implementación de unicode. \\
\hline - Información sobre documentos que complete al registro bibliográfico. \\
\hline $\begin{array}{l}\text { - Acceso a otros recursos desde el propio opac: recursos-e, archivos de imagen y sonido, bases } \\
\text { de datos, revistas-e, motores de búsqueda de internet, registros marc, metadatos, etc. }\end{array}$ \\
\hline $\begin{array}{l}\text { - Acceso en línea al sistema de clasificación, organización e indización de las colecciones de la } \\
\text { biblioteca. }\end{array}$ \\
\hline - Posibilidad de solicitar documentos por préstamo interbibliote \\
\hline $\begin{array}{l}\text {-Ofrecer un servicio de Difusión Selectiva de la Información y creación de portales } \\
\text { personalizados de conocimiento de acuerdo a los intereses de cada usuario. }\end{array}$ \\
\hline
\end{tabular}

\begin{tabular}{|l|}
\hline \multicolumn{1}{|c|}{ Nuevas tendencias a incorporar en los opac } \\
\hline - Uso de metadatos. \\
\hline - Aplicación de la norma sgml. \\
\hline - Empleo del protocolo OAI-PMH. \\
\hline - Consulta en lenguaje natural. \\
\hline
\end{tabular}

prestaciones que se consideran más útiles para satisfacer las necesidades de los usuarios y el valor de sus criterios para determinar la organización, diseño y disposición de la información.

Por último señalar que, a lo largo del estudio, se hacen una serie de valoraciones personales sobre la amigabilidad de las interfaces y otros muchos aspectos que son, cuando menos, opinables y discutibles pues no se han basado en estudios o encuestas sino que se deben a la experiencia profesional y a las impresiones que se perciben en el contacto diario con los usuarios.

\section{Breve "revisión bibliográfica"}

A lo largo del análisis se presenta una propuesta realizada partiendo del estudio de indicadores presentado por otros muchos autores para la evaluación de catálogos. Algunos de estos análisis han sido ofrecidos en los trabajos que se citan a continuación.

En el ámbito de la evaluación de opacs por medio del análisis de la presencia y localización de distintos errores, cabe destacar el trabajo de Ballard (2001) que muestra los resultados del estudio sobre el catálogo de la Adelphi University llevado a cabo en 1991. A lo largo del artículo se expone una extensa y detallada relación de errores producidos por la incorrecta introducción de términos. Algunos ejemplos que se recogen son los siguientes: Anderson (en lugar de Hans Christian Andersen; Aminal en lugar de Animal). Por su parte, Chapman y Massey (2002) estudian la calidad de los catálogos desarrollados por Ukoln en colaboración con las bibliotecas del condado de Essex. Se muestran los procesos, elementos y resultados del proyecto piloto llevado a cabo en la University of Bath en el año 2000. Se trata de un estudio completo y muy elaborado que analiza el porcentaje de errores $y$, a través de éste, describe los niveles de calidad de los registros bibliográficos. Resulta muy interesante la terminología empleada y los códigos de control de errores. En el ámbito español la investigación de Ortego y Bonal (2000) presenta una buena síntesis, aunque breve, sobre los estudios de evaluación y análisis de opacs basados en la presencia de distintos tipos de errores (modelos propuestos por Beall, Dwyer y

Cahn). En el estudio se emplean los "tests de suciedad" como método de evaluación para determinar la existencia de errores de precisión. Se realiza una aplicación práctica sobre los catálogos de las bibliotecas públicas de Aragón, Andalucía y Castilla León. Se buscan secuencias de palabras erróneas representativas: nombres propios de lugar, de personas, de términos relacionados con la descripción bibliográfica y nombres comunes.

En cuanto a los tipos de búsqueda presentes en los opacs se puede señalar el trabajo de Catalán y Prieto (1999) que realizan un interesante y notable análisis sobre la consulta por números o esquemas de clasificación en algunas bibliotecas centrales de universidades españolas. Se trata de una tipología de recuperación escasamente utilizada por dos motivos principalmente: la dificultad de los sistemas de clasificación y la falta de capacidad y precisión del software. Es un buen estudio pero, quizás, está un tanto obsoleto pues se analizan sistemas como Vtls, Sabini, Libertas, Dobis Libis o Absys de los que, algunos de ellos, actualmente han dejado de utilizarse. 
En el análisis global de prestaciones del software cabe mencionar varios extensos y rigurosos trabajos como son: Moscoso (1998) que expone una relación de características (junto con la comparación de las mismas) que debe reunir un opac para ser considerado amigable. Analiza las prestaciones de los opacs de segunda generación: interfaz, página de búsqueda, etiquetas, texto, etc. Es un artículo de obligada lectura que presenta una síntesis profunda de las características, mejoras y los aspectos a desarrollar. Es base fundamental y de referencia para poder definir y analizar los opacs de tercera o última generación que pretenden ser (a pesar de sus deficiencias) los catálogos cuya evaluación se presenta a lo largo de las siguientes páginas. Autores como Rodríguez y Alvite (2002) analizan minuciosamente las prestaciones de Innopac Millenium. Como modelo a seguir hay que destacar la contribución de Ramesh y O'Brien (2000) que presentan un excepcional trabajo en el que analizan y contrastan las prestaciones de seis opacs implementados en bibliotecas del Reino Unido. Los sistemas informáticos estudiados son Talis, Innopac, WebCat, Voyager, Geoweb y Aleph. Se trata de un trabajo muy bien estructurado, con un exhaustivo análisis de las prestaciones de cada software y que se completa con una tabla ilustrativa de características principales de cada catálogo y unos interesantes apéndices.

Existen estudios sobre la evaluación de catálogos colectivos como puede ser el de Ortego y Bonal (2001), que presentan una propuesta de indicadores para la evaluación de

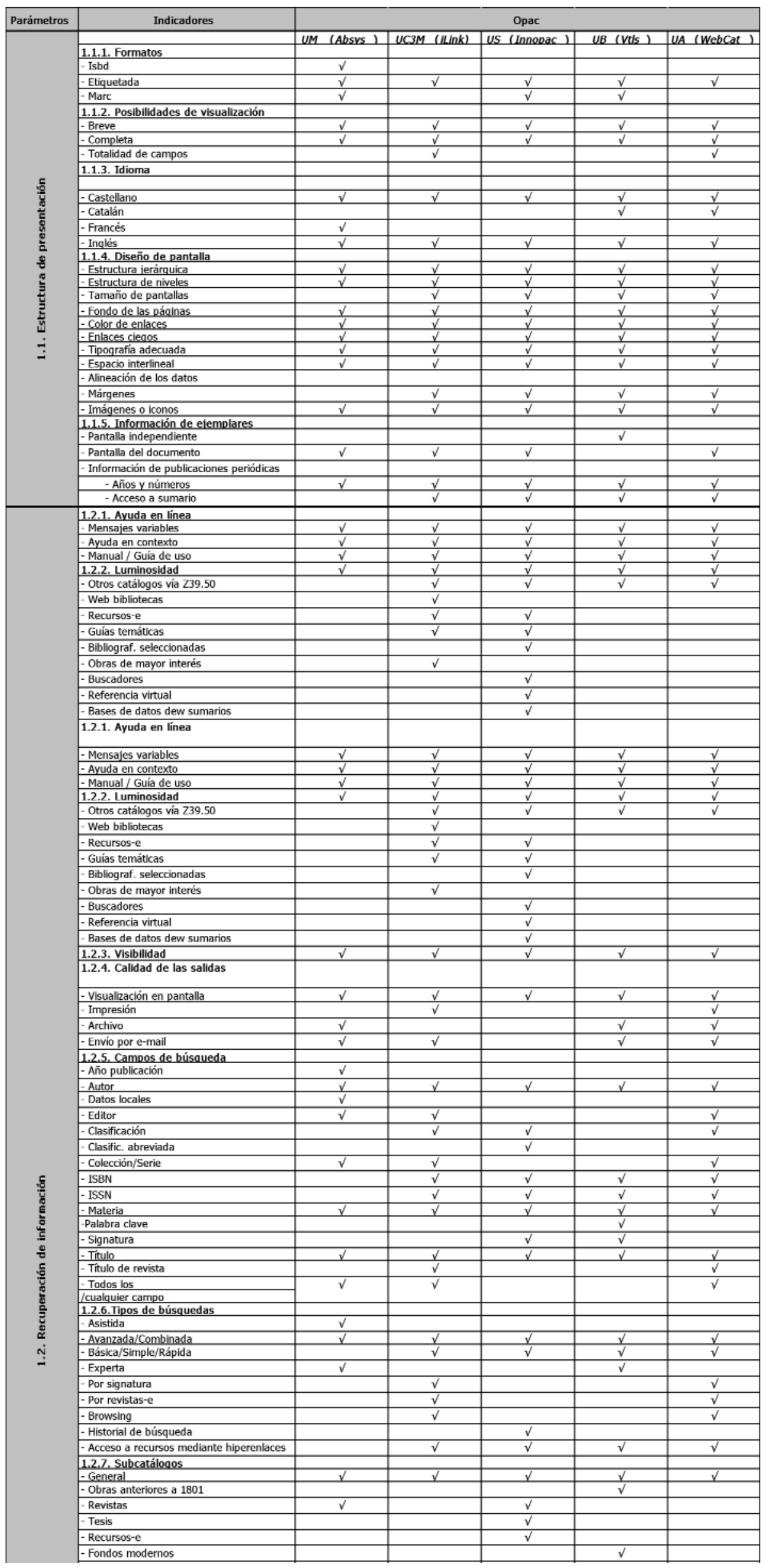




\begin{tabular}{|c|c|c|c|c|c|c|}
\hline & - Obras posteriores a 1820 & & & & $\sqrt{ }$ & \\
\hline & \begin{tabular}{|l} 
- Autoridades \\
\end{tabular} & & & & $\sqrt{ }$ & \\
\hline & - Fondo antiguo & $\sqrt{ }$ & & & & \\
\hline & 1.2.8. Operadores & & & & & \\
\hline & Booleanos & & & & & \\
\hline & and & $v$ & $\gamma$ & 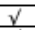 & 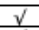 & $\sqrt{v}$ \\
\hline & or & $\frac{1}{v}$ & $\sqrt{ }$ & $\sqrt{ }$ & $\sqrt{ }$ & $\frac{1}{y}$ \\
\hline & not & $\sqrt{v}$ & $\frac{\gamma}{\gamma}$ & $\frac{\gamma}{y}$ & $\frac{v}{v}$ & $\frac{\gamma}{\gamma}$ \\
\hline & xor & & $\sqrt{ }$ & & & $\sqrt{ }$ \\
\hline & Posicionales & & & & & \\
\hline & adj & $\sqrt{ }$ & $\sqrt{ }$ & & & $\checkmark$ \\
\hline & same & $\checkmark$ & $\checkmark$ & & & $\sqrt{ }$ \\
\hline & with & $\sqrt{ }$ & $\sqrt{ }$ & & & $\sqrt{ }$ \\
\hline & near/cerca de & $\sqrt{ } \cdot$ & $\sqrt{ } \cdot$ & $\checkmark$ & & $\sqrt{ }$ \\
\hline & Truncamientos & & & & & \\
\hline & * & $\sqrt{ }$ & & & $\sqrt{ }$ & \\
\hline & $?$ & $\sqrt{ }$ & $\sqrt{ }$ & & & $\sqrt{ }$ \\
\hline & $\$$ & & $\checkmark$ & & & $\mathrm{v}$ \\
\hline & 1.2.9. Limitadores de búsqueda & & & & & \\
\hline & \begin{tabular}{|l|l|}
-Tipo de documento \\
\end{tabular} & $\checkmark$ & $\checkmark \sqrt{ }$ & $\checkmark$ & & $\sqrt{ }$ \\
\hline & - Idioma & & $\sqrt{ }$ & $\sqrt{ }$ & & $\sqrt{ }$ \\
\hline & - Ubicación/Localizac. & & $\sqrt{ } \cdot$ & $\checkmark$ & & $\checkmark$ \\
\hline & \begin{tabular}{|l|}
-Editor \\
\end{tabular} & & & $\checkmark$ & & \\
\hline & - Año de pub. & & $\sqrt{ }$ & $\sqrt{ }$ & & $\sqrt{ }$ \\
\hline & - Ordenar por Fecha & & $\sqrt{ }$ & $\sqrt{ }$ & & $\sqrt{ }$ \\
\hline & - Ord. por Autor & & $\sqrt{ }$ & & & 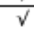 \\
\hline & - Ord. por Titulo & & $\sqrt{ }$ & & & $\sqrt{ }$ \\
\hline & - Ord. por Materia & & $\sqrt{ }$ & & & $\sqrt{ }$ \\
\hline & - Ord. por relevancia & & $\sqrt{ }$ & & & $\sqrt{ }$ \\
\hline & 1.2.10. Fiabilidad de datos/presencia & & & & & \\
\hline & - Errores de qrabación & $\mathrm{v}$ & $\mathrm{v}$ & $\mathrm{g}$ & $\mathrm{y}$ & 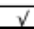 \\
\hline \multirow{28}{*}{ 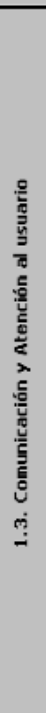 } & 1.3.1. Información sobre: & & & & & \\
\hline & - Nuevas adquisiciones & & $\sqrt{ }$ & & & $\bar{v}$ \\
\hline & - Bibliografia recomendada alumnos & & $\gamma$ & & & $\sqrt{ }$ \\
\hline & - Bibliografia de docencia & & $\sqrt{ }$ & & & \\
\hline & \begin{tabular}{|l|} 
- Reglamento préstamo \\
\end{tabular} & & & & $\mathrm{V}$ & \\
\hline & - Cursos de formación & & $\sqrt{ }$ & $\sqrt{ }$ & $\sqrt{ }$ & \\
\hline & - Signaturas & & & & $\sqrt{ }$ & \\
\hline & 1.3.1. Información sobre: & & & & & \\
\hline & - Nuevas adquisiciones & & $\sqrt{ }$ & & & $\bar{v}$ \\
\hline & \begin{tabular}{|l|} 
- Bïbliografía recomendada alumnos \\
\end{tabular} & & $\sqrt{ }$ & & & $\sqrt{ }$ \\
\hline & - Bibliografía de docencia & & $\sqrt{ }$ & & & \\
\hline & \begin{tabular}{|l|} 
- Reglamento préstamo \\
\end{tabular} & & & & $\sqrt{ }$ & \\
\hline & - Cursos de formación & & $\sqrt{ }$ & $\checkmark$ & $\sqrt{ }$ & \\
\hline & \begin{tabular}{|l|} 
- Signaturas \\
\end{tabular} & & & & $\mathrm{v}$ & \\
\hline & 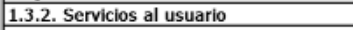 & & & & & \\
\hline & - consulta carnet/ficha de usuario & $\sqrt{2}$ & $y^{2}$ & 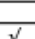 & $\sqrt{7}$ & $\sqrt{7}$ \\
\hline & - Cambio de clave de acceso & $\frac{1}{\sqrt{ }}$ & $\frac{\gamma}{\sqrt{2}}$ & $\frac{\gamma}{\sqrt{2}}$ & & 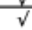 \\
\hline & - Renovar prestamos & $\sqrt{ } \cdot$ & $\sqrt{ } \cdot$ & & & $\checkmark$ \\
\hline & \begin{tabular}{|l|} 
Reserva de obras \\
\end{tabular} & $\checkmark$ & $\checkmark$ & & & $\mathrm{v}$ \\
\hline & 1.3.3. Sollicitudes & & & & & \\
\hline & -Inf. sobre cambio de domicilio de usuario & & $\sqrt{ }$ & & & $\bar{v}$ \\
\hline & \begin{tabular}{|l|} 
- Prest, interbibliotecario \\
\end{tabular} & & $\checkmark$ & $\checkmark$ & & \\
\hline & - Envio de consultas de Inf. bibliográfica & & $\sqrt{ }$ & & $\sqrt{ }$ & \\
\hline & -Envio mensajes, suqerencias, quejas & & $\gamma$ & 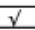 & & $\gamma$ \\
\hline & - Adq. de nuevos títulos (desiderata) & & $\frac{\gamma}{\sqrt{ }}$ & $\sqrt{1}$ & & \\
\hline & - Adq. de ejemplares adicionales & & $\sqrt{ }$ & & & \\
\hline & - Reproducción de fondo antiguo & & & $\checkmark$ & & \\
\hline & - Servicio de fotocopias & & & & $\sqrt{ }$ & \\
\hline
\end{tabular}

Tabla prestaciones de las interfaces de opacs

cos del catálogo de la Biblioteca Daniel Cosío Villegas de El Colegio de México. El método empleado se basa en la evaluación de la existencia de errores que afectan o no a la recuperación de registros bibliográficos. Se acompaña el estudio de una detallada e innecesaria presentación sobre el proyecto de automatización y de reconversión de la biblioteca. El estudio de Zapico (1998) repasa la calidad de los encabezamientos de los opacs de las Bibliotecas Públicas del Estado empleando los indicadores de errores de precisión y de consistencia, establecidos y adaptados por Ortego y Bonal que son los originales propuestos, inicialmente, por Chapman. La aplicación práctica presentada consiste en la comparación de los ejemplos que se presentan en el capítulo 15 de las Reglas de Catalogación (ed. 1995) con los encabezamientos de los registros bibliográficos de los catálogos de bibliotecas públicas españolas. Se recogen tres muestras sobre el campo "autor" en distintas fechas y diversas bibliotecas. Se

catálogos colectivos universitarios, los cuales fueron tomados partiendo de las propuestas de evaluación realizadas sobre catálogos norteamericanos. Se toman como referente los estudios de Shelia Inter sobre la calidad de Oclc y Rlin, los trabajos de Lisa Romero de la Universidad de Illinois, así como los de Lei Zeng relacionados con la calidad de registros en lengua china de Oclc-Rlin. La aplicación práctica se realiza sobre el catálogo Rebiun tomando una muestra de 35 registros. Se trata de un interesante análisis que presenta la síntesis de la evaluación realizada a través de unas representativas tablas con parámetros, indicadores, objetivos, datos, métodos y medidas de referencia utilizadas.

El análisis de la calidad de los registros bibliográficos ha sido un tema tradicional en la evaluación de catálogos. A modo de ejemplo, se pueden señalar los trabajos de Quijano y Ariola (1998) quienes presentan un estudio (que, desde mi punto de vista, tiene un título poco representativo del contenido) en el que analizan el control de calidad de los registros bibliográfi- trata de un original y curioso análisis que pone de manifiesto cuestiones que hoy en día siguen estando pendientes como son la falta de referencias y la inconsistencia en los catálogos.

A modo de compendio o resumen, es de destacar la investigación llevada a cabo por Ríos (1991) que presenta una síntesis de los diversos aspectos presentados en los estudios realizados sobre la relación existente entre los usuarios y el opac. Se afirma en el estudio que "no pretende ser una revisión bibliográfica exhaustiva sino recoger los estudios que han parecido más interesantes sobre cada uno de los temas". Pienso que tal recogida se puede considerar como un buen estado de la cuestión que utiliza una pertinente y actualizada bibliografía y que además resume, magistralmente, las teorías expuestas sobre los requisitos que deben cumplir los catálogos. Por último, hay que señalar la investigación de Goodchild, (1996) en la que se analiza el nivel de uso y la accesibilidad que presentan los catálogos, además de la calidad de los mismos. 


\section{Metodología}

En primer lugar se ha procedido a la búsqueda y selección de bibliografía sobre la evaluación y el control de calidad de los catálogos. Se ha observado que existe un grupo muy numeroso de estudios sobre el tema desde el punto de vista del usuario y la recuperación de información que lleva a cabo. El número de trabajos que analizan las herramientas desde la perspectiva de la catalogación, la estructura, el almacenamiento y la normalización de la información es mucho menor. No obstante, realizar una precisa normalización de los puntos de acceso es fundamental y es el aspecto que, según Herrero (1999) realmente "aumenta la funcionalidad de los mismos como elemento indispensable para la recuperación de la información". Son destacables los excelentes estudios que ha realizado Frías acerca de la estructura de los registros bibliográficos de los opacs y las necesidades reales de información de los usuarios.

En segundo lugar se ha elaborado una propuesta de parámetros e indicadores de medición y evaluación. Se incluye la finalidad, intención y utilidad de cada indicador y se añade una fórmula para la obtención de resultados cuantificables. Los indicadores se han contrastado con el análisis de las prestaciones de algunos de los sistemas informáticos disponibles actualmente en las bibliotecas universitarias españolas. Son aplicados para comparar las interfaces y las posibilidades de búsqueda, y no estudian el nivel de especificidad temática, la cobertura temática, idiomática y geográfica de los fondos bibliográficos ni tampoco la tipología documental. En tercer lugar se han añadido unas "fórmulas", aplicables en la evaluación que pueden servir para obtener resultados cuantitativos y cualitativos del análisis llevado a cabo.

Los catálogos se han analizado a lo largo de los meses de enero a marzo de 2002 de forma remota por medio de su interfaz web, única versión disponible para el usuario (excluyendo, por tanto, el entorno de trabajo particular de cada software) en cualquier Sigb actual. Como ya se ha indicado, para la realización del estudio se han tomado los ejemplos de los catálogos de bibliotecas universitarias concretas y las prestaciones

\begin{tabular}{|l|}
\hline Codina Bonilla, Lluis \\
El libro digital y la www / Lluis Codina. - Madrid : Tauro, D. L.2000 \\
$274 \mathrm{p} .-$ - (Comunicación y lenguajes) \\
ISBN 84-88605-54-4 \\
Edición (Informática) \\
Sistemas de información \\
$655.28: 681.31$
\end{tabular}

Cuadro 1: registro en formato Isbd tomado de la Universidad de Murcia que las mismas han decidido implementar (y no se ha evaluado sistemas en general, pues suelen tener mayores posibilidades de explotación que las escogidas en la presentación de un catálogo concreto) y que son las que aparecen a continuación:

-Univ. de Murcia (UM), Absys:

http://gargoris.cpd.um.es/Absys/

-Univ. de Barcelona (UB), Vtls:

http://eclipsi.bib.ub.es/Vtls/catalan/index.html

—Univ. de Sevilla (US), Innopac (Fama):

http://fama.us.es/

-Univ. Carlos III de Madrid (UC3M), Unicorn (iLink): http://biblioteca.uc3m.es/uhtbin/webcat/

—Univ. de Alicante (UA), Unicorn (WebCat):

http://gaudi.ua.es

\section{Definición de indicador}

Se puede definir como: parámetro de evaluación y medición de un producto o servicio que, tras el análisis de resultados cuantitativos-cualitativos y la comparación con modelos aceptados, sirven para determinar el grado de calidad del producto o servicio sometido a un proceso de evaluación. Su utilidad proviene de la capacidad de comparar el nivel de calidad de un parámetro o característica con respecto a unos niveles establecidos previamente.

Las pautas de la Ifla recomiendan para cada indicador presentar su definición, denominación, objetivos que prevé conseguir, etc. Según la norma UNE 66904-90 deben comprender: valores previstos, tolerancias y características de los atributos; criterios de aceptación y rechazo; así como método de medición y ensayo.

En esta propuesta se exponen 17 indicadores que se agrupan en tres parámetros generales. La mayoría se debe aplicar tras la obtención de datos estadísticos y después de consultas y búsquedas. Además, dependiendo de las potencialidades de la interfaz de consulta, se podrán extraer resultados del mayor o menor nivel de calidad. En ocasiones, se observará que la aplicación de un indicador en la evaluación de un único catálogo no significa nada, pero sí será realmente útil si se comparan los resultados con la evaluación de un opac de otro sistema informático.

1. Parámetros, indicadores y fórmulas que permiten la comparación de prestaciones de los opacs de distintos sistemas informáticos.

1.1. Estructura de presentación.

1.1.1. Formatos. 


\begin{tabular}{l}
\hline ISBN: $84-88605-54-4$ \\
CDU: 681.31:002 \\
CDU: 002:681.31 \\
Autor Principal: Codina, LLuis \\
Título: El libro digital y la www / Lluis Codina \\
Publicación: [Madrid] : Tauro, D.L. 2000 \\
Descripción Fisica: 274 p. \\
Título de Serie: (Comunicación y Lenguajes) \\
Bibliografia: p. 267-274 \\
Materia: Edición electrónica \\
Materia: Recuperación de la información \\
Materia: Páginas Web - Diseño
\end{tabular}

Cuadro 2: registro en formato etiquetado tomado de WebCat de la Universidad de Alicante.

Las posibilidades que ofrecen en este caso son variadas y se pueden usar indistinta o simultáneamente:

- Tipo ficha: aparece el registro bibliográfico con el orden y la puntuación exacta de la norma Isbd. Un ejemplo sería el que aparece en el cuadro $n^{\circ} 1$. Se utiliza únicamente en el catálogo de la biblioteca de la $U M$.

—Etiquetada: la información se muestra precedida de etiquetas que indican los datos que vienen a continuación. Este método es muy usado actualmente para intentar distanciarse de los catálogos manuales tradicionales y porque presenta los datos de una manera más clara (cuadro $n^{-} 2$ ).

La presentación etiquetada se ofrece en la biblioteca de la $U B$, la $U M$, la biblioteca universitaria de Sevilla $(U S)$, siendo la única presentación de la $U A$ y de la UC3M. Es la más adecuada para los usuarios al ser la más clara y lógica para las personas que desconocen los formatos de catalogación. Pese a esto hay que señalar que, tal y como afirma Moscoso (1998) "no hay razón para que en un campo etiquetado como título si-

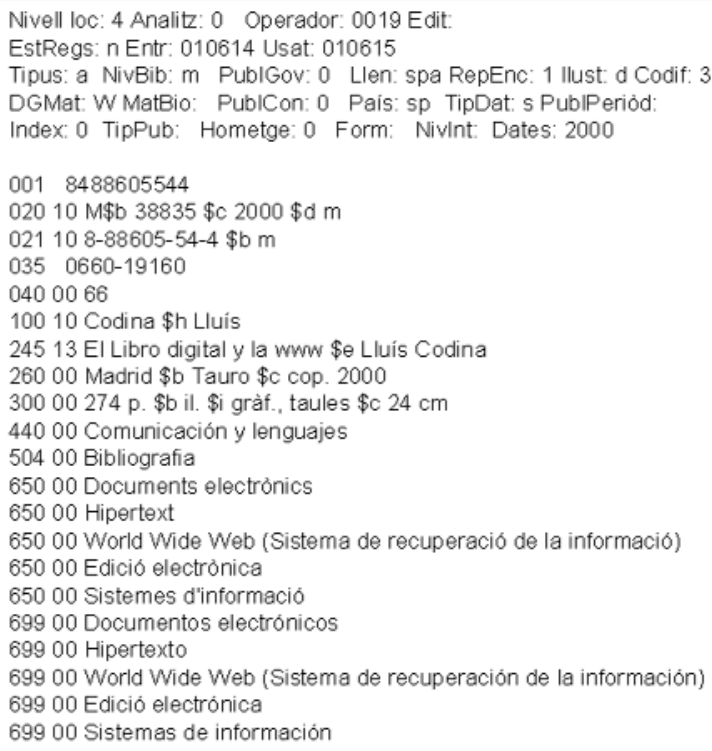

Cuadro 3: Registro en formato marc tomado de Vtls en la Universitat de Barcelona. ga incluyendo traductores, coordinadores, prologuistas, etc.".

-Formato marc: presentación de los datos de registros bibliográficos precedidos de sus etiquetas propias (cuadro $\mathrm{n}^{\mathrm{o}}$ 3). Se utiliza en los menús desplegables de los catálogos de la $U B, U S$ y $U M$. No lo presenta la $U A$ ni la $U C 3 M$. Su utilidad de cara al usuario no bibliotecario es prácticamente nula.

\subsubsection{Posibilidades de visualización.}

Este aspecto se refiere a la posibilidad de seleccionar diferentes configuraciones para la visualización de los resultados obtenidos. En todos los catálogos analizados, tras ejecutar una búsqueda aparece un listado de resultados en formato breve. Innopac presenta: $\mathrm{n}^{\mathrm{o}}$ de orden de recuperación de los documentos, título, año de publicación, número de entradas encontradas, casilla de marcar o desmarcar documentos. WebCat e iLink ofrecen: signatura, título, mención de responsabilidad, autor, tipo de documento, $\mathrm{n}^{\mathrm{o}}$ de ejemplares y año de publicación, casilla de marcar o desmarcar registros. Absys señala: número de orden del registro, título, mención de responsabilidad, casilla de marcar o desmarcar. Vtls arroja la lista de títulos y números de ejemplares. En los casos en que se recuperan recursos a texto completo, o en formato electrónico, el texto se presenta tras un enlace. WebCat e iLink añaden la posibilidad de seleccionar más o menos campos de visualización dentro de un formato (opciones de brief, all, full o todos, completo, breve). La diferencia entre todos/all y completo/full es que la primera ofrece los campos fijos del formato marc y la segunda no. Es una opción con un interés realmente escaso desde punto de vista del usuario.

—Fórmulas a aplicar:

[nº de estilos de visualización de registros]

\subsubsection{Idioma.}

Es posible modificarlo a la hora de hacer la consulta en la $U A$ (castellano, inglés, incluyéndose como idioma el valenciano) y en la UC3M (castellano, inglés); la $U B$ se presenta en castellano, catalán e inglés mientras que la $U M$ lo ofrece en castellano, francés e inglés; el catálogo de la $U S$ es accesible en inglés y castellano.

—Fórmulas a aplicar:

[ $\mathrm{n}^{\mathrm{o}}$ de idiomas de presentación del opac]

\subsubsection{Diseño de pantalla.}

Algunos elementos importantes que se deben tener en cuenta son los siguientes:

-Estructura jerárquica. En todos los casos se ha aplicado una estructura jerárquica de páginas web que, 
si se ha diseñado bien, permitirá visualizar los contenidos fácilmente y de forma organizada.

-Estructura de niveles. En general se suele utilizar: superior (opciones generales de información/comunicación con el usuario); intermedio (ventana y tipos de búsquedas); inferior (otras opciones de navegación).

- Tamaño de las pantallas. La página nunca debe ser más grande que una pantalla. Un ejemplo de este aspecto se puede apreciar en el opac de la $U M$, en donde la página está diseñada con un tamaño excesivamente grande. Lo ideal es componer páginas no superiores a una pantalla y media para poder visuali-

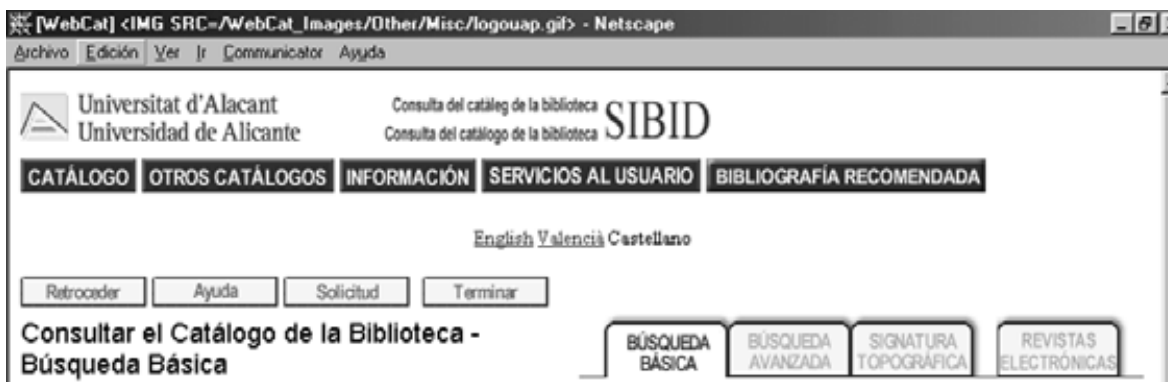
Búsqueda Básica BASICA

6 Palabra clave $\subset$ List.alfab, $\subset$ Exacto

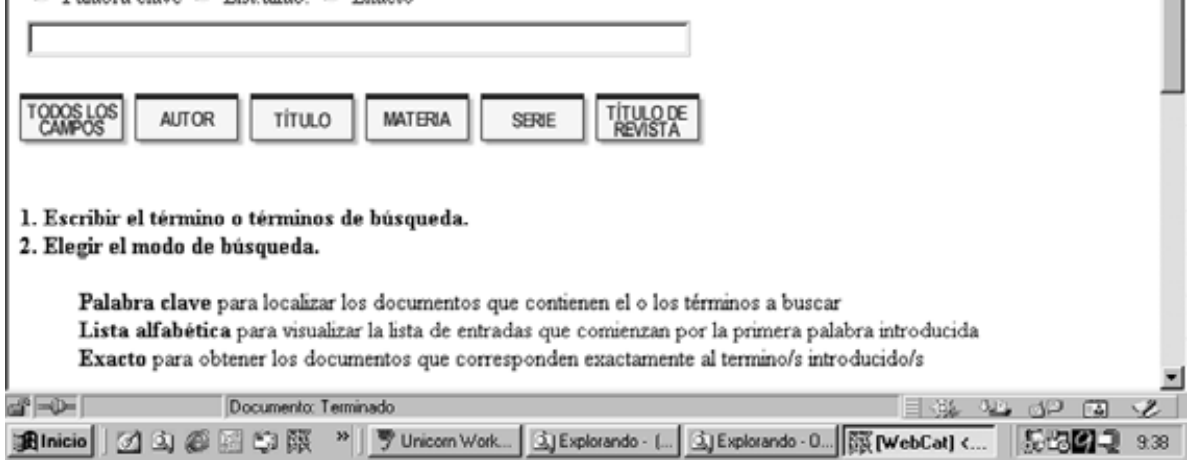
Universidad de Alicante zarla sin necesidad de utilizar las barras de desplazamiento, facilitando considerablemente la lectura. El tamaño actual de configuración es de $1024 \times 768$ píxeles, no obstante todavía es frecuente encontrar de 600x800. Una solución puede ser diseñar pantallas de $1024 \times 768$ y dejar márgenes en blanco en los laterales de forma que se vean correctamente en $800 \times 600$.

—Fondo de las páginas. Debe ser en color blanco o, en su defecto, se debe elegir uno claro o suave.

- Color de enlaces. El color distintivo para los hiperenlaces debe ser único para los no visitados y debe emplearse otro tono para los ya examinados.

-Enlaces ciegos. Hay que evitar, en la medida de lo posible, la aparición en las páginas de mensajes de "página en construcción" pues da muy mala impresión. Los mensajes de "...File not found", se deben comprobar chequeando páginas y probando enlaces.

- Tipografía adecuada. Cada sistema informático suele tener un tipo de letra por defecto (los tipos Arial o Helvética se encuentran comúnmente en la mayoría de entornos de trabajo). Hay unos más usados que otros, por ejemplo Arial se escoge muy a menudo pues resulta una escritura muy clara. Existen dos grupos de tipografías principales: "Serif" (se aplica si la fuente es menor de 12 píxeles y se usa en el cuerpo principal de una pantalla para facilitar la lectura del contenido); "Sans serif" (cuando la fuente es mayor de 12 píxeles, pues el texto se aprecia mejor). Lo ideal es intentar utilizar una única tipografía dentro de cada pantalla, incluso dentro del diseño general de todo el conjunto. Las mezclas en una misma pantalla pueden inducir a confusión y desorientación. No se debe abusar del empleo de estilos como negritas, cursivas y, mucho menos, subrayados (se pueden confundir con hiperenlaces); en los opacs analizados se observa gran variedad en este sentido. Los tipos más usados por la $U S$ son Arial y Times new roman combinados con varios colores y no se usa el estilo de negrita. La $U A$ emplea principalmente Times new roman; mientras que en la $U C 3 M$ se mezcla este tipo de letra con otros distintos.

-Espacio interlineal. Es un aspecto que suele pasar desapercibido pero es muy importante pues si las líneas de la pantalla se disponen muy cerca, dará mala impresión la sensación de abigarramiento y resultará bastante incomoda la lectura para el usuario. Una separación de dos espacios debe ser suficiente o, en algunos casos, de un espacio y medio.

-Alineación de los datos. Deben aparecer a la izquierda de la pantalla. En la presentación de los documentos con formato etiquetado, las etiquetas deben estar escritas en mayúsculas, justificadas a la derecha y separadas por dos puntos de los datos del registro bibliográfico. La finalidad de estas pautas de diseño es ofrecer una rápida y clara identificación de los elementos que componen un registro y distinguirlo, a su vez, del resto de los elementos de la página. La $U M$ y $U S$ presentan etiquetas en letra minúscula y justificadas a la izquierda; por su parte la $U B$ ofrece etiquetas en mayúscula pero alineadas a la izquierda y no a la derecha. Por último los catálogos de $U C 3 M$ y $U A$ presentan las etiquetas en minúscula y justificadas a la derecha.

- Márgenes. Es necesario analizar su tamaño para que la información se presente de manera atractiva, de 
fácil y cómoda lectura. No hay que olvidar que la mayor cantidad de información debe disponerse en la parte superior de cada pantalla. El opac de la $U M$ no tiene en cuenta este aspecto y es un grave error.

- Imágenes o iconos. Existen distintos formatos gráficos utilizables en las páginas de los opacs. Lo más frecuente es utilizar imágenes gif, pues son muy sencillas, con pocos colores y muy delimitadas. En el caso de que el opac ofrezca acceso a documentos de uso exclusivo para una determinada comunidad de usuarios, debe indicarse a través de un icono específico. Resulta útil duplicar los elementos de navegación al principio y al final de cada página (sobre todo si tienen un tamaño superior a una pantalla y media). Es importante la inclusión de etiquetas o iconos de "Retroceder", "Avanzar", "Pasar página”, "Arriba", "Abajo" etc. Todos deben ir acompañados de un texto identificativo para evitar que el usuario tenga que descifrar su significado. El opac que más imágenes o iconos ofrece es Absys, aunque también son muy variados en Innopac. WebCat presenta multitud de botones ("Retroceder", "Hacia atrás", Hacia delante", "Ir a", etc.); "Volver, "Salir", "Más" son algunos de iLink. Botones como "Comenzar de nuevo", "Próximo registro" o "Borrar registros guardados" aparecen en Innopac.

-Fórmulas a aplicar:

[ $\mathrm{n}^{\mathrm{o}}$ de páginas de tamaño superior a las dimensiones de una pantalla y media/n $\mathrm{n}^{\mathrm{o}}$ total de pantallas]

[ $\mathrm{n}^{\mathrm{o}}$ de enlaces ciegos $/ \mathrm{n}^{\mathrm{o}}$ total de enlaces del opac]

[Empleo de única tipografía]

[Empleo de varias tipografías]

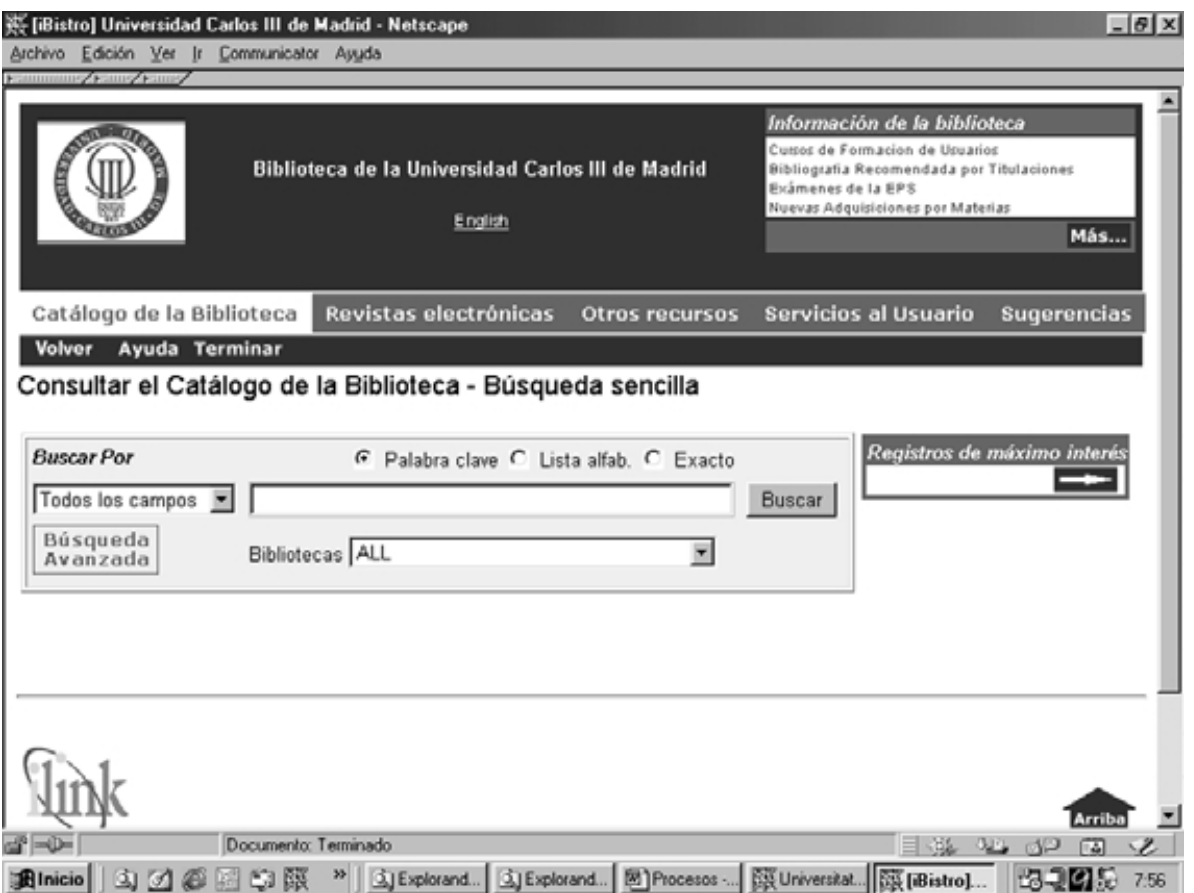

Universidad Carlos III de Madrid dos]

[Aplicación de estilos: negrita, cursivas, subraya-

[Espacio interlineal conveniente]

[Márgenes aceptables]

[Disposición de mayor cantidad de información: zona superior, inferior, centrada]

[Inclusión de imágenes]

[Iconos con texto explicativo]

[Inclusión de elementos de navegación]

1.1.5. Información de ejemplares.

Resulta más útil que aparezca a continuación del registro bibliográfico y no en una página independiente. Preferentemente debe existir un único código de barras para cada uno de los ejemplares o volúmenes (es más fácil la identificación de los mismos y, por ejemplo, ayuda a realizar reservas a títulos de documentos o a ejemplares concretos de un mismo documento). En la información de los fondos bibliográficos se debe indicar si el documento está disponible para su consulta; si está prestado (en ese caso se debe indicar la fecha de devolución); si es un material de uso restringido; si está en proceso de adquisición; si está reservado a un usuario; si está pendiente de recolocación en la estantería correspondiente, etc. También puede resultar interesante añadir en la información de ejemplares la tipología del documento, por ejemplo: manual, monografía, disco, diapositiva, obra de consulta (diccionario, anuario, etc.), obra de creación, etc.

En Vtls la información de ejemplares aparece en una página distinta a la del registro bibliográfico. Sin embargo, en Innopac, WebCat, iLink y Absys la información de ejemplares se ofrece en la misma pantalla, lo que hace que la visualización sea más cómoda y rápida. WebCat presenta en la parte superior de la pantalla del registro bibliográfico la opción "Saltar a la localización/info de disponibilidad" que permite visualizar directamente la información de los ejemplares de un documento que se ofrece en la parte inferior de la misma pantalla.

En cuanto a la información sobre fondos de publicaciones periódicas, lo ideal es ofrecer desde el opac información de los años, números, volúmenes, etc. que existen en la biblioteca. Vtls 
ofrece información de los fondos de revistas dentro de la etiqueta "Numeració" y además, muestra el sumario de cada número de revista; Absys ofrece los números y años de cada título de revista; Innopac informa de la identidad, ubicación, signatura, fondos, último número recibido y da acceso al sumario. WebCat e iLink también ofrecen esta información dentro del registro de cada título de revista.

-Fórmula a aplicar:

[Sistema de muestra de ejemplares en misma página o en página independiente]

[Aparición del n⿳丷o de ejemplar o copia]

[Visualización del estado del ejemplar]

[Indicación del tipo de documento]

[Información de años, números, volúmenes de revista en la misma pantalla]

[Acceso al sumario]

\subsection{Recuperación de información.}

\subsubsection{Ayuda en línea.}

Supone una de las mayores aportaciones de los catálogos automatizados respecto de los manuales. Se considera un elemento imprescindible y debe ser accesible de manera explícita desde cualquier parte del sistema. Con todo, lo ideal sería que se presentase un diseño y funcionamiento lo más simple, claro y accesible posible, para que el usuario no necesitase acudir a consultar la ayuda. Es preciso mencionar que el nivel y el grado de desarrollo de las ayudas, además de sus características, suele venir determinado por el esfuerzo de elaboración de las guías de ayuda realizado en cada biblioteca. Se pueden distinguir distintos tipos:

- Los mensajes variables que se transforman según la página a la que se acceda. Su función es servir de aviso de las opciones disponibles en cada momento. Realmente funcionan como "asistentes" en la búsqueda.

-Otro tipo de ayuda sería aquella que se mantiene estable y uniforme durante todo el proceso de consulta. Son conocidas como "ayudas en contexto". WebCat e iLink ya la ofrecen pero poco desarrollada y en lengua inglesa en el caso de iLink. Absys ofrece un sistema de ayuda bastante completo y una guía de uso. $V t l s$ ofrece una ayuda únicamente referida a los tipos de búsqueda y la localización de los documentos. La ayuda en pantalla de Innopac es muy amplia pues incluye una guía rápida y otra avanzada. Está bien estructurada con explicaciones pormenorizadas y muy ilustrativas. Una especie de ayuda muy extensa y detallada, denominada "Manual del usuario", "Guía de uso" o "Guía de consulta" se ofrece en todos las he- rramientas analizadas. Un interesante y reciente trabajo sobre el tema es el de Zapico Alonso (2002).

-Fórmula a aplicar:

[Presencia-ausencia de ayuda]

[Tipología de ayuda presente en el opac]

\subsubsection{Luminosidad.}

Entendida como "el número de enlaces que contiene hacia otras sedes web" Codina (2000). Se analizarían en este punto las posibilidades de enlazar desde el propio catálogo a otras páginas y recursos de búsqueda de información como por ejemplo webs de instituciones, otros catálogos, bases de datos, recursos electrónicos, recursos de información en internet, buscadores, etc. La biblioteca de la $U A$ ha implementado en WebCat una mínima y pobre relación de enlaces a otros recursos y sedes web desde los botones de "Otros catálogos" (catálogos Z39.50 y enlaces a páginas web). ILink en la UC3M ofrece una interfaz más completa pues da acceso, a través de "Otros recursos" a catálogos, webs de bibliotecas, recursos electrónicos y guías de recursos por materias. La biblioteca de la $U B$, a través de Vtls, permite enlazar con el Ccuc, con catálogos de distintas bibliotecas nacionales, de universidades y centros de investigación, de bibliotecas públicas, catálogos de publicaciones periódicas, del $P a$ trimonio Bibliográfico así como otros de ámbito europeo e internacional. Desde Innopac, en la US se accede a bibliografías seleccionadas, dossier electrónico, ver registro de usuario, otras bibliotecas vía Z39.50, búsqueda por separado en varias bibliotecas (Autónoma de Madrid, Complutense, etc.), búsqueda en $R e$ biun, etc.

$$
\begin{gathered}
\text { «El enfoque es el del análisis y } \\
\text { valoración de la adaptación y } \\
\text { los ajustes materializados en } \\
\text { las distintas bibliotecas univer- } \\
\text { sitarias, y no las funcionalida- } \\
\text { des completas que ofrecen } \\
\text { Absys, iLink, Innopac, Vtls o } \\
\text { Webcat» }
\end{gathered}
$$

-Fórmula a aplicar:

[nํำ de enlaces a otros recursos de búsqueda de información]

[no de enlaces a otros opacs]

[nำ enlaces a otras instituciones]

\subsubsection{Visibilidad.}

Codina (2000) la define como "grado en el cual una web es enlazada por otras webs". Por ejemplo, re- 


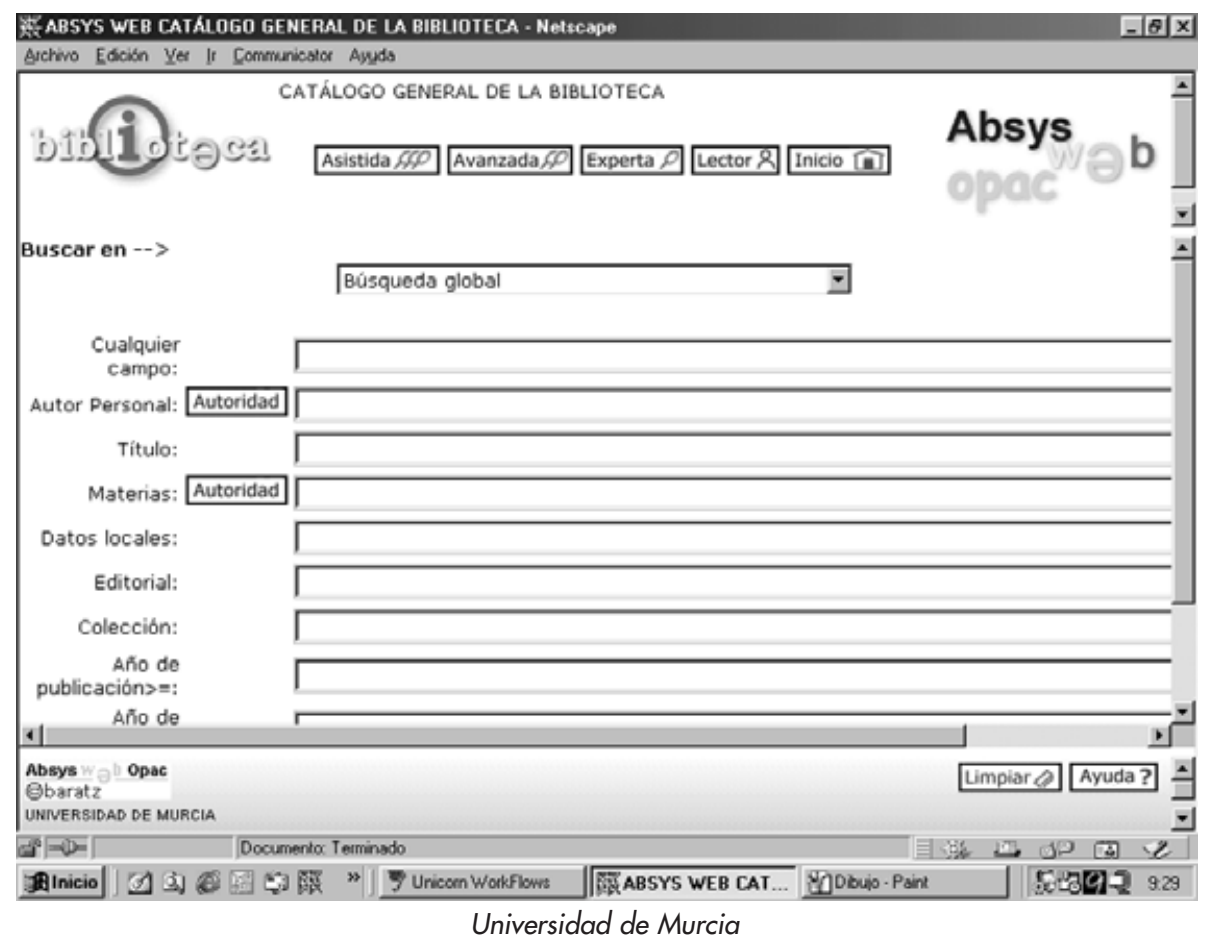

sulta interesante conocer el número y tipo de páginas que enlazan nuestro catálogo desde otras bibliotecas, universidades, facultades, departamentos, institutos de investigación, instituciones culturales, etc.

-Fórmula a aplicar:

[n ${ }^{\circ}$ de visitas realizadas desde la misma institución a la que sirve el opac]

[ $\mathrm{n}^{\mathrm{o}}$ de vistas recibidas desde sitios externos]

\subsubsection{Calidad de las salidas.}

Se analiza la posibilidad de poder obtener los resultados por diferentes vías:

—Visualización en pantalla: presentan esta opción básica todos los catálogos analizados.

-Impresión en papel: permiten hacerlo todos los catálogos, bien directamente, como opción predeterminada del sistema (tal es el caso de Innopac, WebCat e iLink que ofrece "Imprimir con formato" e "Imprimir texto"); bien indirectamente imprimiendo la pantalla empleando las utilidades del navegador como es posible hacer en Vtls y Absys.

-Archivo: permiten guardar registros Vtls, Absys y WebCat.

—Envío por correo-e: opción disponible en $\mathrm{Vtls}$, Absys, WebCat e iLink.

—Posibilidad de diseñar otros formatos de salida personalizados, etc.

—Fórmula a aplicar:

[n⿳⺈ de formatos de salida del opac]

\subsubsection{Campos de búsqueda.}

A la hora de realizar consultas en el catálogo hay que valorar la variedad de campos de búsqueda que presenta así como la potencialidad de los mismos.

La $U A$ y la $U C 3 M$ ofrecen seis campos de recuperación de información (todos los campos; autor; título, materia, serie, título de revista). Además, permiten la búsqueda por especificación de campo como editorial, Isbn, etc. que, aunque no aparezcan en la pantalla, se pueden utilizar mediante la combinación del término a buscar y el operador \{\} . Por ejemplo: la búsqueda de la editorial Cátedra sería: cátedra \{260\}. Opción muy útil si se conoce, pero raramente el usuario

es tan experto.

La US ofrece los siguientes campos: autor, título, autor-título, materia, Isbn/Issn, signatura, clasificación y clasificación abreviada. La $U M$ presenta en la búsqueda asistida: cualquier campo, autor personal, titulo, materias, datos locales, editorial, colección y año de publicación mientras que en la avanzada incluye autor, título, materia, edición y colección.

Vtls presenta en la consulta simple título, autor, materia, palabra clave, signatura, Isbn, Issn; mientras que en la combinada se puede utilizar la palabra clave de título, de autor, de materia o general. En la búsqueda experta no hay elección de campos.

El orden de presentación también es importante y, en todos los casos analizados, se limitan a presentar la información de los registros siguiendo el orden de las Isbd (por ejemplo: no agrupan a todos los responsables del contenido de una publicación en un sólo campo, sino que se mantiene el encabezamiento principal, la mención de responsabilidad y las entradas de autores secundarios: información redundante, confusa y desconocida por el usuario inexperto).

-Fórmula a aplicar:

[ $\mathrm{n}^{\mathrm{o}}$ de campos para buscar $/ \mathrm{n}^{\mathrm{o}}$ total de campos disponibles en un registro]

[nº de campos "explícitos" para buscar/no total de campos disponibles en un registro]

\subsubsection{Tipos de búsquedas.}

Se analizarán aspectos como: tipología de búsquedas, repetición de estrategias, enlaces hipertexto, bús- 
queda relacional o en varios catálogos a la vez, integración y/o acceso a recursos electrónicos, limitaciones de búsqueda que presenta, etc. Es fundamental que el opac presente buenas referencias. Su finalidad es dirigir a un usuario desde un encabezamiento utilizado al realizar una búsqueda al uniforme, normalizado o autorizado que se ha establecido en la biblioteca (ello se logra con un buen control de autoridades).

En cuanto a las tipologías de consultas disponibles:

La $U A$ y $U C 3 M$ presentan cuatro tipos: básica (se denomina también rápida en iLink); avanzada; signatura topográfica y revistas electrónicas. Tras la consulta se puede afirmar que la avanzada de ambos sistemas es una búsqueda que se debiera denominar asistida pues sus funciones y potencialidades ya las hace la básica. Es decir, la rápida de iLink y básica de WebCat permiten, añadiendo operadores, realizar búsquedas tan complejas como las de la avanzada.

La $U M$ presenta tres tipos: asistida, avanzada y experta. El catálogo de la $U S$ ofrece simple y avanzada. Por su parte, la $U B$ ofrece simple, combinada y búsqueda experta.

Otros sistemas de búsqueda de información son el de navegación, búsqueda por listados, etc. Todas estas designaciones son sinónimos de browsing. Se trata de una operación que consiste en introducir un término de búsqueda, visualizar un listado y seleccionar las referencias para, más tarde, ver el registro completo de cada uno de los seleccionados. Los listados pueden ser de autores, títulos, materias, series, etc. Para conocer los antecedentes, así como algunos proyectos y catálo-

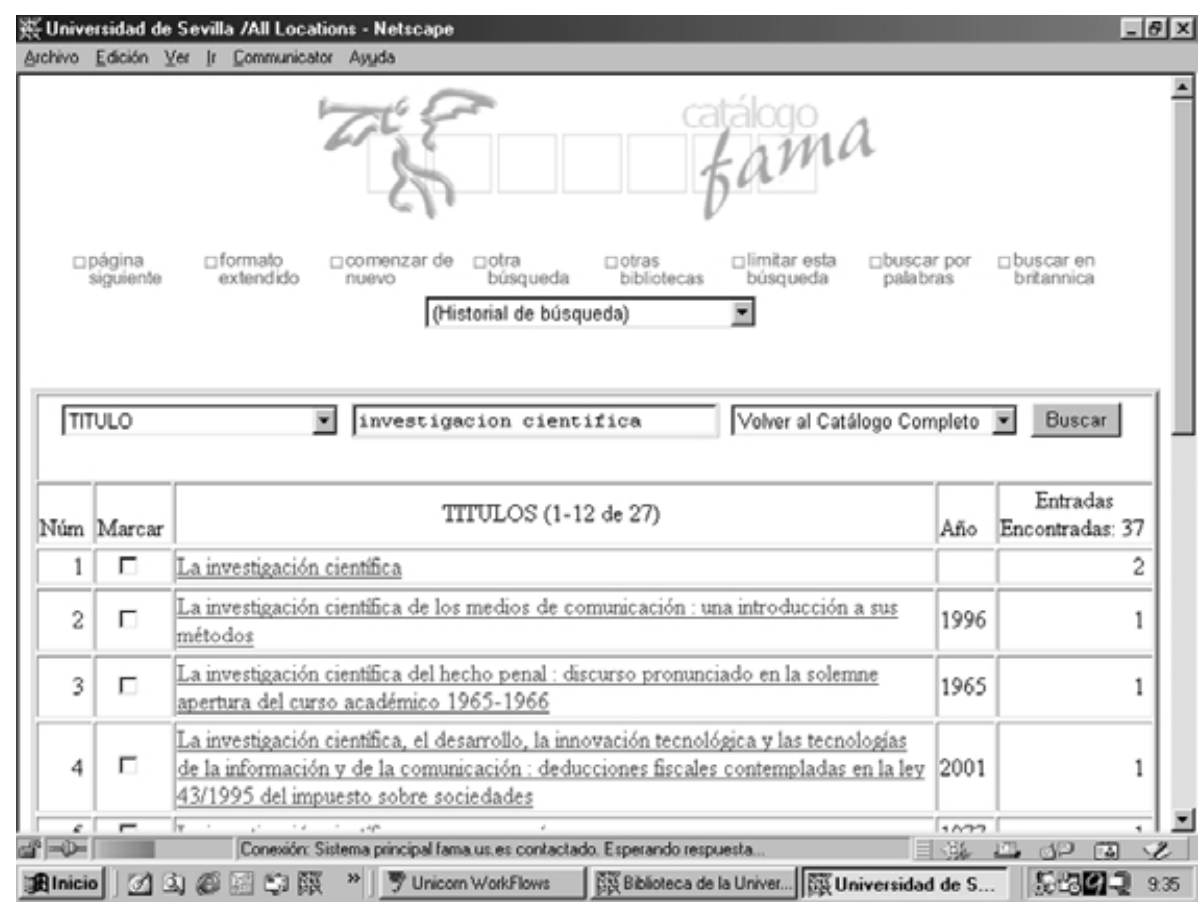

Universidad de Sevilla gos experimentales basados en el mismo, resulta muy útil consultar el trabajo de Fernández-Molina y Peis (1999). Un ejemplo de este tipo de acciones es el modo de búsqueda de lista alfabética de WebCat e iLink. Absys, Innopac y Vtls no han adoptado esta opción de búsqueda.

Se valorará especialmente la presencia de un historial de búsqueda que permita visualizar todas las que se hayan realizado que contemple la posibilidad de reutilizarlas, de combinarlas, etc. Aunque el catálogo de Innopac no es el único que posee esta herramienta sí es el que la tiene disponible para los usuarios; por ejemplo, la última versión de Absys (la 6.0) ya dispone de esta cómoda opción.

Los opacs que ofrecen la descripción y el acceso de recursos electrónicos disponibles en la Red, por medio del campo 856 del formato marc, son los siguientes: la $U A$ lo ofrece a través de la consulta de revistas electrónicas. La UC3M permite, por ejemplo, la consulta a texto completo de los documentos de trabajo de la universidad y el acceso a 25 títulos de libros electrónicos de informática por medio del sistema Safari; se accede a ellos de forma conjunta desde "Otros recursos" y "Recursos electrónicos" o bien de forma individual, realizando la consulta en la ventana de búsqueda del opac. En ambos casos desde el campo acceso electrónico se accede a su texto. La US también ofrece el acceso a 212 libros-e a través del mismo sistema. En la $U B$ se ofrece el acceso a los sumarios de las revistas electrónicas y la US permite el acceso a las revistas electrónicas desde la opción "Conectar a la revista" del catálogo de recursos electrónicos (contienen las revistas a texto completo y las bases de datos) y desde el catálogo general. La $U M$ no ha integrado el acceso a recursos electrónicos y sólo permite la consulta de sumarios, abstracts y texto completo de las revistas suscritas a través de los servicios EbscoHost y Science Direct.

-Fórmula a aplicar:

[Tipología de búsquedas ofrecidas]

[Posibilidad de reutilización y combinación de estrategias]

[Existencia/Inexistencia de enlaces hipertexto]

[Existencia de un fichero histórico de búsquedas]

1.2.7. Subcatálogos disponibles. 
La US presenta: catálogo general, de obras anteriores a 1801 , de revistas, de tesis y de recursos electrónicos. La $U B$ ofrece el catálogo de fondos modernos y el de posteriores a 1820. Además, se ofrece un catálogo de autoridades que permite recuperar información por nombre de persona, entidad, congreso, nombre geográfico y tema o materia. La $U M$ ofrece el catálogo de publicaciones periódicas y el general; desde la página inicial se ofrecen también los subcatálogos: fondo antiguo y novedades trimestrales.

-Fórmula a aplicar:

[Existencia/Inexistencia de subcatálogos]

[Tipología de subcatálogos disponibles]

1.2.8. Operadores para la estrategia de búsqueda.

El usuario debe traducir su necesidad de información en una pregunta empleando un lenguaje que pueda ser procesado por el motor de búsqueda. Se analizarán en este apartado aspectos como: operadores empleados, diferenciación de mayúsculas o minúsculas, acentos, apóstrofos, palabras vacías, espacios en blanco, etc. La mayoría de sistemas de recuperación utilizan el sistema booleano que consiste en combinar una serie de términos mediante los operadores lógicos o booleanos (and: intersección; or: unión; not: exclusión).

-WebCat e iLink presentan: booleanos (and, or, not xor); posicionales (same, with, near, adj); truncamiento (\$, ?). No distinguen las mayúsculas de las minúsculas; los acentos pueden ser tecleados en los términos de búsqueda; los apóstrofos no los considera y las palabras vacías son ignoradas por ambos. No obstante, el operador " " se emplea cuando una palabra vacía forma parte fundamental del término de búsqueda.

-Innopac ofrece los operadores booleanos en español (y, o, no, y no) y el posicional (cerca de). Permite truncamientos con $*$ e ignora los artículos a comienzo de título.

-Absys ofrece operadores booleanos y truncamientos (signos * ?). Además, en la búsqueda experta soporta también los posicionales (adj, cerca, mismo, con) y de comparación $(>,<,=,>=,<=)$ en búsquedas numéricas.

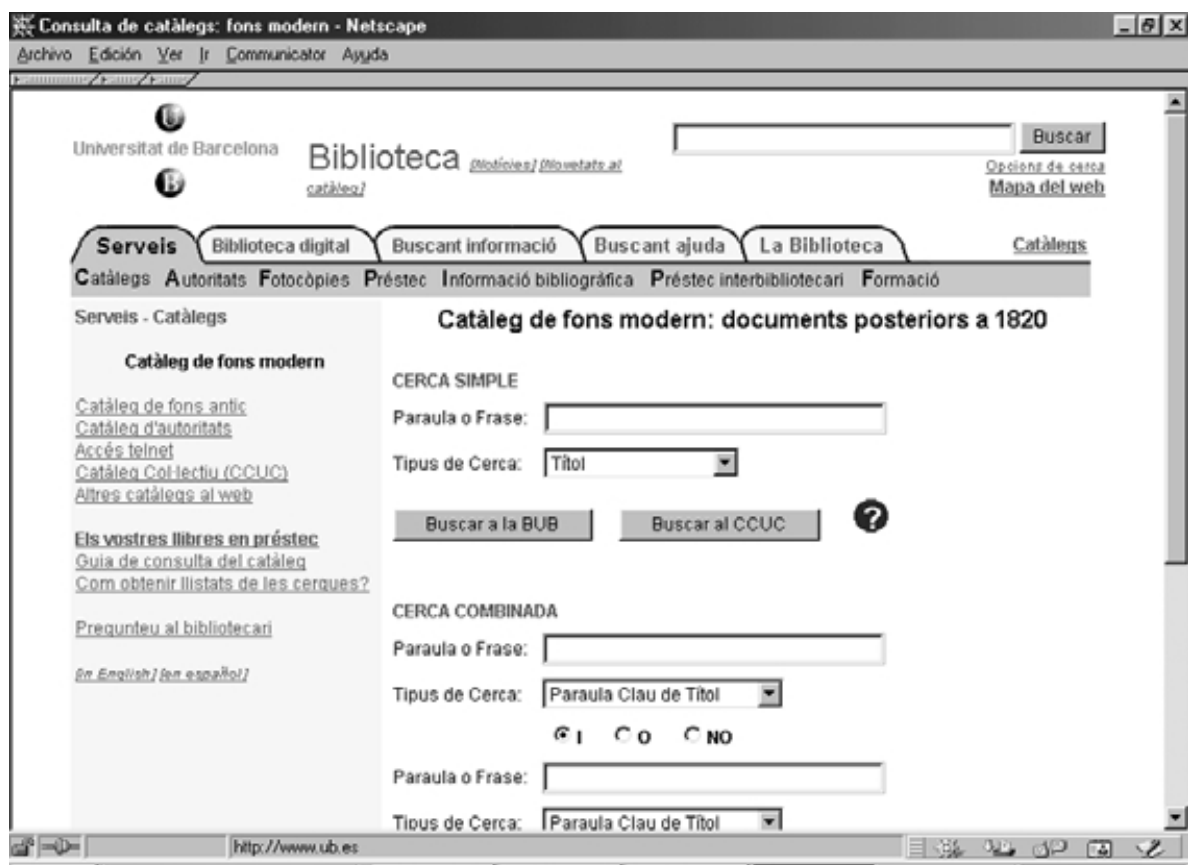

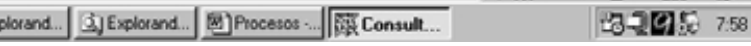

Universidad de Barcelona

—Vtls ofrece operadores booleanos y truncamientos.

En cuanto a la amigabilidad, sería necesario estudiar aspectos como la facilidad para realizar consultas y formular estrategias de búsqueda por medio de una presentación agradable y de un uso intuitivo de las opciones, la facilidad para visualizar los documentos, etc. El opac debe ser lo suficientemente claro como para que el usuario no necesite un curso de formación ni un manual para poder consultarlo. Esta facilidad de uso debe unirse a la efectividad de recuperación. Una interfaz debe ser fácil de usar y este punto está directamente vinculado con la interactividad o capacidad de diálogo con el usuario (Rodríguez Bravo; Alvite Díez, 2002).

Todos los catálogos analizados ofrecen un lenguaje de recuperación sencillo y las pantallas presentan opciones que orientan al usuario sobre sus utilidades. El acceso al catálogo desde internet facilita mucho la consulta al usuario y ha sido el motivo de una mayor generalización de su acceso. En este sentido, es importante que los catálogos se consulten usando los propios botones del sistema y no los del navegador. De todos los analizados, los más amigables son Innopac, iLink y WebCat pues presentan con mucha claridad cada una de las opciones.

—Fórmulas a aplicar:

$\left[\mathrm{n}^{\mathrm{o}}\right.$ de operadores permitidos $/ \mathrm{n}^{\mathrm{o}}$ total de operadores existentes]

[Distinción de letras mayúsculas-minúsculas]

[Necesidad de escribir acentos]

El profesional de la información, v 13, n. 1, enero-febrero 2004 
[Reconocimiento de palabras vacías]

[Tipos de búsqueda especificadas]

[Operadores de consulta explícitos]

[Campos de búsqueda detallados]

\subsubsection{Limitadores de búsqueda.}

Los resultados obtenidos tras realizar una búsqueda pueden limitarse o refinarse mediante distintos criterios: la $U M$ permite limitar por tipo de documento (monografías, publicaciones periódicas, música, vídeos, mapas, recursos electrónicos y partituras); en la $U S$ se puede acotar por idioma, formato del documento, tipo de documento, ubicación, editor, año y ordenar por fecha. En la $U A$ y $U C 3 M$ es posible restringir las consultas por año de publicación, idioma, localización y formato. También permite ordenar los resultados de la búsqueda por Autor, Título, Materia, Año de publicación y Orden de relevancia.

-Fórmula a aplicar:

[nํㅡㄹ de opciones de limitación de búsqueda]

\subsubsection{Fiabilidad de los datos.}

La detección de errores y el estudio de la frecuencia de su aparición en los catálogos ha sido objeto de estudio por muchos autores. Ortego y Bonal (2000) proponen el uso de test de suciedad como forma de evaluación de catálogos automatizados y aplican la propuesta de Chapman (1994) que distingue entre: errores de precisión o de caracteres y de consistencia o producidos en la aplicación de las normas. Al respecto, Frías (1994) define los indicadores de consistencia como "aquellos que se deben a una incorrecta utilización de las normas y de su interpretación uniforme". En cuanto al estudio de la tipología de faltas tipográficas, Jacso (1993) las clasifica según dos clases: errores de omisión y de comisión". Los primeros están referidos a la ausencia de datos o campos bibliográficos, mientras que los segundos son incorrecciones tipográficas u ortográficas.

\section{«La ayuda en línea supone una de las mayores aportaciones de los catálogos automatizados respecto de los manuales»}

Herrero (1997) clasifica los errores ortográficos en cuatro grupos: de inserción (un carácter insertado dentro de una palabra); de omisión (cuando es omitido); de transposición (dos caracteres adyacentes de una palabra son intercambiados); de sustitución (un carácter es remplazado por otro diferente). "Aunque no existe una norma específicamente definida para el nivel de calidad aceptable para la catalogación de los registros bibliográficos, parece claro que, debiera marcarse por debajo de 1. Es decir, una frecuencia-promedio mayor de 1 error por registro indicaría un nivel deficiente de calidad, y cuanto más se acercara a 0 dicha frecuencia, la calidad aumentaría" (Quijano; Ariola, 1998) Reeb (1984) por su parte aplica criterios cuantitativos para la medición de calidad y propone un nivel máximo de error de 0.8 para los registros bibliográficos: "el número de errores entre el número de registros tiene que ser menor o igual a 0.8 " para que tenga una calidad aceptable. Para Rodríguez Yunta (1999) la presencia de errores en bases de datos es difícil de evitar pues viene determinada por múltiples causas (aplicables igualmente a los opacs):

- Características del indizador: grado de conocimiento de la materia; conocimiento de las necesidades reales del usuario; inexperiencia; capacidades de concentración, lectura comprensiva, análisis y síntesis.

-Defectos en la construcción de los lenguajes documentales: riqueza de relaciones y ayudas; ambigüedades e imprecisiones; desequilibrios en el grado de especificidad.

—Propiedades del documento: dificultad propia de la materia; complejidad del texto: presentación y escritura.

- Características de los procedimientos de trabajo: grado de automatización de los procesos; criterios establecidos para el análisis documental; existencia de normas y reglas claras.

Algunos errores observados en los opacs analizados son:

En la $U A$, aparecen los siguientes errores de grabación: ausencia de letras en una palabra, por ejemplo, antropología filosofic en vez de antropología filosófica. En autores: Lawrence, David Herbert aparece en la base de datos como Lawrence, D, Lawrence DH, Lawrence David Herbert 1885-1930, Lawrence David Herbert. El autor Domínguez Machuca, J. A., aparece también como Domínguez Machuca, José Antonio. El encabezamiento de una obra de la autora $M^{a}$ Ramona Domínguez Sanjurjo aparece como Domínguez Sanjurjo, $M^{a}$ Ramón. Algunos autores cuyo apellido comienza por $\mathrm{O}$ se han introducido comenzando por 0 (cero), es el caso de Odell, Felicity, que aparece como Odell, Felicity; Oreilly, John figura como Oreilly, John; Odriscoll, M. J. como Odriscoll MJ. El término Traducion en vez de Traducción aparece con frecuencia en el área 245 de la $U C 3 M$ y también en el catálogo de la $U M$.

En cualquier caso se puede afirmar que, la presencia de errores es mayor en el área de publicación, se- 


\section{Revista sobre documentación,}

\section{bibliofecas y nuevas fecnologías}

\section{de la información}

EL PROFESIONAL DE LA INFORMACION es una revista bimestral dirigida a los que trabajan en cualquier tarea relacionada con la adquisición, tratamiento documental

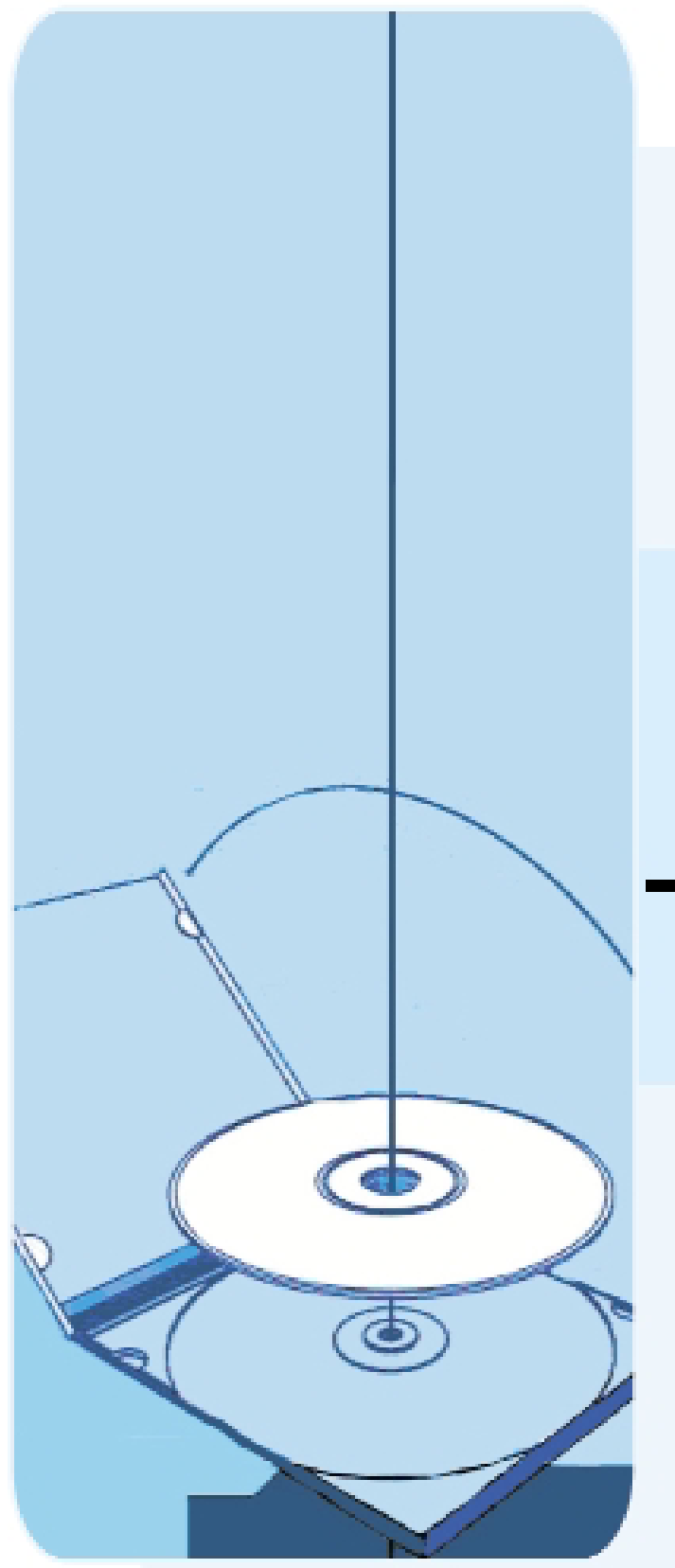
o informático, almaccnamicnto y difusión de datos y documentos, asi como en diserio de sistemas de informacion y en la ensenanza de todas estas tecnicas.

Leer EPI es la forma idónea de estar al dia sobre el mundo de la información y de conocer cuáles son los cambios más significativos que se van produciendo. EPI anade antecedentes $e$ informacion de fondo sobre las noticias para situarlas en su contexto o compararlas. Incluye comentarios y analiza tendencias.

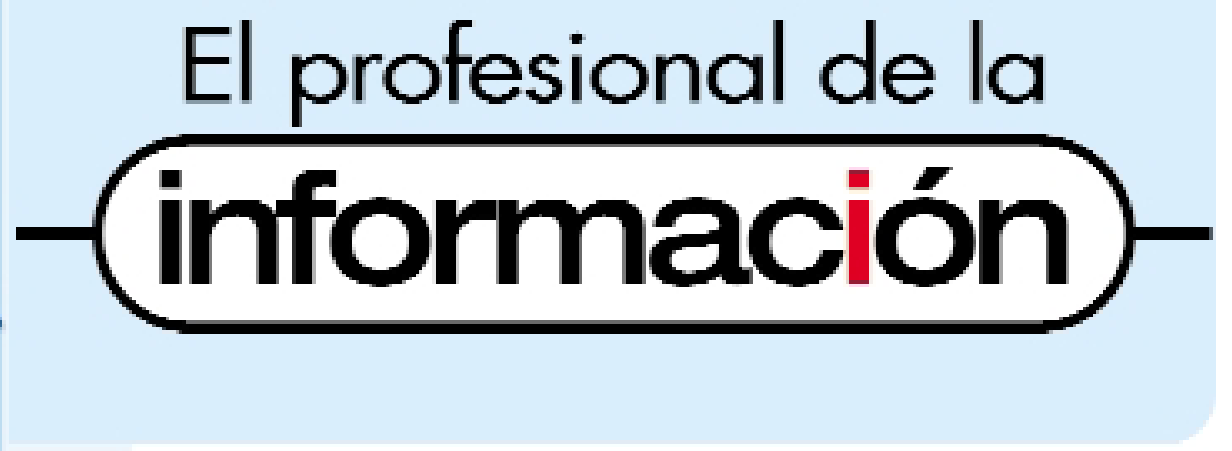

Mercado de la información: estadísticas, aspectos legales, políticas, empresas, productos y servicios Recursos informativos en las redes Sistemas de información Internet, multimedia y soportes opticos Gestion del conocimiento Lenguajes documentales Terminología

DIRIGIDA POR:

Tomats Baigct

Pedro Hipolo

PUBLICTOAD:

Alice Keefes akecfer Burrakis.es
SUSCRIPCIONES

Extenza-lurpin whenath,

SG6 IHN. Herls, Reino Unido

lel.: + +44-1462672555

Fax: +44.14624809 .47$

subscriplionsenturpinild.com

ATENCIÓN AL SUSCRIPTOR

Swels lnigrmation survices

Nánolas 227, 2" planta

08013 Borcelong

kel.: +34.932081970

Fax: 134.9.32 081 971

opelschen Bes swelsblockwell.com $\because$ Taylor \& Francis Tayylor \& Francis Group 
rie, título y mención de responsabilidad así como en las notas.

-Fórmulas a aplicar:

[ $\mathrm{n}^{\mathrm{o}}$ de registros con errores $/ \mathrm{n}^{\mathrm{O}}$ total de registros]

[ $\mathrm{n}^{\mathrm{o}}$ de errores en un registro/ $\mathrm{n}^{\mathrm{o}}$ total de registros]

[nº de errores de grabación/ $\mathrm{n}^{\mathrm{o}}$ total de registros]

1.3. Atención y comunicación con usuario.

1.3.1. Información de la biblioteca sobre distintos aspectos.

Se valora con este indicador la relación y las posibilidades de contacto y comunicación del usuario con la biblioteca a través de los servicios y utilidades que ofrece el opac. Por ejemplo:

-Bibliografía recomendada por los profesores a los alumnos: WebCat e iLink.

-Bibliografía de docencia para el profesorado: disponible en iLink.

-Reglamento de préstamo: útil información que la biblioteca de la $U B$ ha decidido difundir a través del opac con el software de Vtls.

- Cursos de formación ofrecidos por la biblioteca: iLink, Innopac y Vtls han introducido la información de este servicio.

-Signaturas: es conveniente, y resulta muy útil, informar (mediante un enlace a otra página informativa o, incluyendo esta información en la ayuda, etc.) de la estructura y composición de las signaturas de las colecciones. El opac de Vtls es el único que lo hace desde la opción de "Localización de documentos", dentro de la guía de consulta del catálogo.

-Formula a aplicar:

[Tipología de la información ofrecida]

[Existencia de explicación y ejemplo de signaturas]

1.3.2. Servicios al usuario.

Los básicos, aquellos que tradicionalmente ofrecía la biblioteca de forma presencial o vía telefónica, han sido implementados en el opac los siguientes:

—Consulta de ficha/carné de usuario o registro de usuario: esta información está disponible en todos los catálogos analizados.

- Cambio de clave de acceso es posible modificar la contraseña de acceso en: Absys, iLink y WebCat.

-Renovación de préstamos: se puede hacer desde Absys, WebCat e iLink.
-Reserva de obras prestadas: la autoreserva de documentos prestados o no disponibles en un momento determinado se puede hacer en Absys, iLink y WebCat.

-Fórmula a aplicar:

[no de servicios al usuario vía web ofrecidos por medio del opac]

\subsubsection{Solicitudes.}

En este punto se analiza la posibilidad del envío y la petición de información y servicios por parte del usuario hacia la biblioteca.

-Información sobre cambio de domicilio: iLink y WebCat sí la recogen.

-Petición de obras por préstamo interbibliotecario: Innopac e iLink permiten realizarla a través del propio opac.

—Envío de consultas de información bibliográfica: en los opacs de iLink e Innopac se ha integrado un formulario de recogida de solicitudes de información.

—Envío de mensajes, sugerencias, quejas: iLink, WebCat y Innopac.

-Petición de desideratas: se contempla la solicitud de nuevos títulos o mayor número de ejemplares de obras ya disponibles. Se puede realizar en Innopac e iLink.

-Reproducción de obras de fondo antiguo: se puede pedir en Innopac.

—Petición de fotocopias: Vtls.

-Fórmula a aplicar:

[no de elementos de comunicación directa entre la biblioteca y el usuario]

\section{Conclusiones}

Tras el análisis expuesto en las páginas anteriores, se puede concluir que los indicadores propuestos responden de manera satisfactoria y son un punto de partida para llevar a cabo un análisis sobre las prestaciones de los opacs de cualquier software. La idea presentada es adecuada para evaluar cualquier catálogo de manera que se puedan observar claramente tanto sus deficiencias como sus puntos fuertes. Es cierto que se han presentado algunos indicadores más teóricos que otros (en los que la aplicación práctica es más fácil) sin embargo, la visión global que se obtiene tras el análisis es aceptable. Resulta necesario advertir que en cada herramienta analizada se han observado una serie de carencias que son consecuencia, muchas veces, de las limitaciones del propio programa informático o que se deben a los criterios y decisiones tomadas por el 
personal que diseña y mantiene las prestaciones disponibles. Además, hay que tener en cuenta, que en cada biblioteca se ofrece la aplicación con un mayor o menor nivel de desarrollo que en otras.

\section{«El opac debe ser lo suficiente- mente claro como para que el usuario no necesite un curso de formación ni un manual pa- ra poder consultarlo»}

Decididamente, el catálogo con mejores y potentes herramientas de búsqueda lo ofrece Innopac. Sin embargo, su diseño y estructura de la información no es tan claro y limpio como los de Unicorn que, desde mi punto de vista, presentan la interfaz más sencilla de cara al usuario. Absys ha mejorado bastante con respecto a otras versiones y aplicaciones concretas del catálogo de la biblioteca analizada y las posibilidades de recuperación por tipo y campos de búsqueda son muy completas. No obstante, el opac de la $U M$ debiera modificar la visualización de las pantallas pues en todas hay que hacer scroll, cuando muchas veces sería innecesario. Además, sería necesario que empezara a integrar y ofrecer las revistas y los recursos electrónicos en el propio catálogo y no de manera independiente y separada del mismo. Por otra parte, aun no ha instalado la última versión de Absys (Absys 6) en la que el opac ofrece mayores posibilidades ${ }^{1}$. Resultará atrevido apuntar que, quizás, la biblioteca de esta universidad tiene un enfoque relativamente conservador a la hora de activar determinadas funcionalidades que son opcionales y que podrían poner en marcha. Algunos ejemplos son: disponer de un subcatálogo específico para acceder a recursos electrónicos y no hacerlo de forma separada, aumentar los criterios de restricción en búsquedas, los formatos de salida y/o visualización, activar el acceso a índices (browsing) en algunos campos (véase por ejemplo esta opción, activada en el catálogo de Rebiun (también con Absys) en búsquedas sobre el título, etc.

El diseño de Vtls es muy sencillo y presenta una gran ventaja respecto al resto: la posibilidad de utilizar cada uno de los tipos de búsqueda en una misma página común sin necesidad de cambiar a otra pantalla. Me parece muy novedosa la opción de que se haya producido un acercamiento en la integración del opac dentro de la propia página web de la biblioteca, de manera que resulta muy fácil seleccionar otro tipo de servicios desde el propio catálogo (por ejemplo: préstamo, fotocopias, cursos de formación, etc.) sin que el usuario tenga la sensación de abandonar la biblioteca para utilizar la herramienta de consulta de sus colecciones. Este aspecto de integración en la web de la propia bi- blioteca también se contempla en iLink pero el diseño de las pantallas es muy diferente en cada una de las opciones.

\section{A modo de valoración final.}

Como "mejoras" alcanzadas por los opacs actuales pueden señalarse los siguientes aspectos: se observa un gran avance en el diseño y personalización de los catálogos, se incorporan unos frames permanentes que se combinan con elementos que muestran el estilo particular de la biblioteca. Se confirma que cada día existe una mayor cantidad de información de la biblioteca integrada en una plataforma de recuperación de información como es, en origen, el opac. Su diseño se ha simplificado y su apariencia es similar a la que muestran los motores de búsqueda. El catálogo es capaz de ofrecer información sobre el estado y la localización de los documentos en tiempo real (prestados, de consulta, en encuadernación, en adquisiciones, en recolocación, etc.). Las posibilidades de recuperación aumentan y es posible encontrar información sobre editoriales, disponibilidad de materiales anejos, etc. La implementación de las técnicas del hipertexto permiten el acceso a los textos completos de los documentos (artículos de revistas-e, libros-e, obras de referencia-e, documentos de trabajo, etc.) además de interrelacionar información contenida en distintos ficheros. El opac se puede configurar en distintas lenguas según país y/o comunidad autónoma. Además de las opciones de limitación, perfeccionamiento y reutilización de estrategias, ya incluyen criterios de relevancia que permiten refinar las búsquedas. Mediante el protocolo Z39.50 se ha conseguido la conexión y consulta de otros catálogos sin salir de la interfaz de la propia biblioteca. El uso del campo 856 (Localización electrónica y acceso) del formato marc que ha permitido una representación

Nueva dirección de Swets Information Services

Las oficinas en España de la agencia de suscripciones Swets Information Services se han trasladado a:
Nápoles 227, $2^{\mathrm{a}}$ planta
08013 Barcelona

$$
\text { Tel.: +34-93208I } 970
$$$$
\text { Fax: }+34-932081971
$$ 
y un enlace entre el registro y el recurso electrónico que describe.

En cuanto a las "deficiencias" manifiestas son destacables las siguientes: la mayoría siguen sin poder implementar Unicode, lo que supone no poder introducir todos los idiomas existentes con sus caracteres propios y sin transcripciones ni adaptaciones (es fundamental para lenguas como árabe, ruso, eslavo, checo, etc.). No obstante, es necesario señalar que la versión Vtls Classic sí dispone de esta opción.

Los opacs deben dar un salto cualitativo y cuantitativo en la oferta de información y empezar a completar os datos bibliográficos con información sobre índices, resúmenes, portadas, primeros capítulos de obras, contribuciones y partes de obras colectivas (actas, comunicaciones y ponencias de congresos, recopilaciones de trabajos académicos, libros homenaje, antologías, etc.), biografías de autores, reseñas de libros, etc. Las bibliotecas todavía siguen sin ofrecer el acceso desde sus catálogos a otros recursos mientras que ya empiezan a aparecer en el mercado herramientas como, por ejemplo $S F X$, que ofrecen la búsqueda en multitud de registros (marc, Dublin Core) y en distintas herramientas (catálogos, bases de datos, revistas-e, buscadores) y todo ello desde una misma y única plataforma de búsqueda. El usuario debe tener información en el opac del sistema de clasificación, organización e indización de los documentos. Como herramientas de búsqueda y de localización de información deben dar la posibilidad de solicitar documentos por préstamo interbibliotecario cuando no son localizados con el propio catálogo. El tradicional servicio de difusión selectiva de la información de las bibliotecas debe ser ofrecido por medio del opac completándose con la creación de portales personalizados de conocimiento de acuerdo a la segmentación de los intereses y las necesidades de cada comunidad de usuarios.

Como "nuevas tendencias o directrices" necesarias a incorporar podemos señalar que resulta imprescindible el uso de metadatos para describir e integrar documentos electrónicos en el opac. Se hace necesaria la implantación de lenguajes de marcas específicos, así, se deberá aplicar la norma sgml utilizada por los metadatos para describir recursos en la Red. "Sgml se puede utilizar para crear una gran variedad de documentos y usarlo, además, para proporcionar acceso y control a multitud de formatos de información en línea" (Ortiz, 1997). Habrá que estudiar las posibilidades del empleo del protocolo OAI-PMH (Open Archives Initiative-Protocol for Metadata Harvesting) para el intercambio de metadatos codificados con Dublin Core.
Como último requisito al que se debe tender es el de conseguir que los opacs se puedan consultar utilizando el lenguaje natural. Este tipo de interfaz permitiría realizar una recuperación de información más pertinente y eficiente. Quizás sea una utopía pero se trata de uno de los requisitos o características que Hildreth o Mitev planteaban para los catálogos de tercera generación.

En definitiva, se hace necesaria la exploración de nuevos estándares de organización y recuperación de información más flexibles y potentes. Todo ello sin perder nunca de vista las necesidades e intereses de los usuarios a los que atendemos. Nuestro papel, como profesionales y expertos en organizar la información y facilitar el acceso a la misma, estará cada vez mas relacionado con la evaluación y planificación de los sistemas de organización, búsqueda y recuperación de información.

\section{Nota}

1. La $U M$ ha migrado recientemente de la versión 5.1 .5 a la 6 con posterioridad a la finalización del estudio que aquí presentamos.

\section{Bibliografía}

Alvite Díez, Ma Luisa; Rodríguez Bravo, Blanca. "Evaluación de interfaces de opacs implementadas con Unicorn en las universidades madrileñas". En: Jornadas de bibliotecas digitales, 2002. Consultado en: 03-10-03. http://mariachi.dsic.upv.es/jbidi2002/Camera-ready/Sesion1/S1-2.pdf

Alvite Díez, Ma Luisa; Rodríguez Bravo, Blanca. "Les interficies web dels opac en les biblioteques universitàries espanyoles". En: Item, 2002, n. 31, pp. 77-92.

Ballard, T. Typhocraphical errors in library databases, 2001. Consultado en: 12-01-03.

http://faculty.quinnipiac.edu/libraries/tballard/typoscomplete.html

Brockman, J. "Just another management fad? The implications of TQM for library and information services". En: Aslib proceedings, 1992, v. 44, n. $7 / 8$, pp. $283-288$.

Catalán Vega, Marcos Antonio; Prieto Castro, Elisa. "Recuperación por sistema de clasificación en los opacs de las bibliotecas universitarias españolas". En: Boletín de la Anabad, 1999, enero-marzo, v. xlix, n. 1, pp. 161-173.

Chapman, Ann. "Up to standard? A study of the quality of records in a shared cataloguing database". En: Journal of librarianship and information science, 1994, v. 26, n. 4, pp. 201-210.

Chapman, Ann; Massey, Owen. "A catalogue quality audit tool”. En: Library management, 2002, v. 23, n. 6-7, pp. 314-324.

Cummings, J.; Johnson, R. "The use and usability of SFX: context-sensitive reference linking". En: Library hi tech, 2003, v. 21, n. 1, pp. 70-84.

Codina, Lluis. El llibre digital y la www. Madrid: Tauro, 2000.

D’Alòs-Moner, Adela. "Calidad total en los centros de documentación, servicios de información y bibliotecas". En: Jornadas españolas de documentación automatizada, 1994, pp. 288-293.

Daniel E. "Quality control of documents". En: Library trends, 1993, v. 41, n. 4 , pp. 644-664.

Fernández-Molina, Juan Carlos; Peis, Eduardo. "Uso de esquemas de clasificación para mejorar las prestaciones de visualización (browsing) de los catálogos en línea". En: III Encuentro de Isko-España: organización del conocimiento en sistemas de información y documentación, 1997, pp. 295-305. 
Ejersuite - Pagina Principal

\section{infroestructuro}

Archivo Edción Ver Favoritas

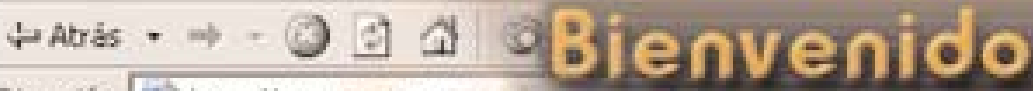

Dirección hittp://ever-tear

Gracias por haber eleqido EverSuite I

ovversuiteoy

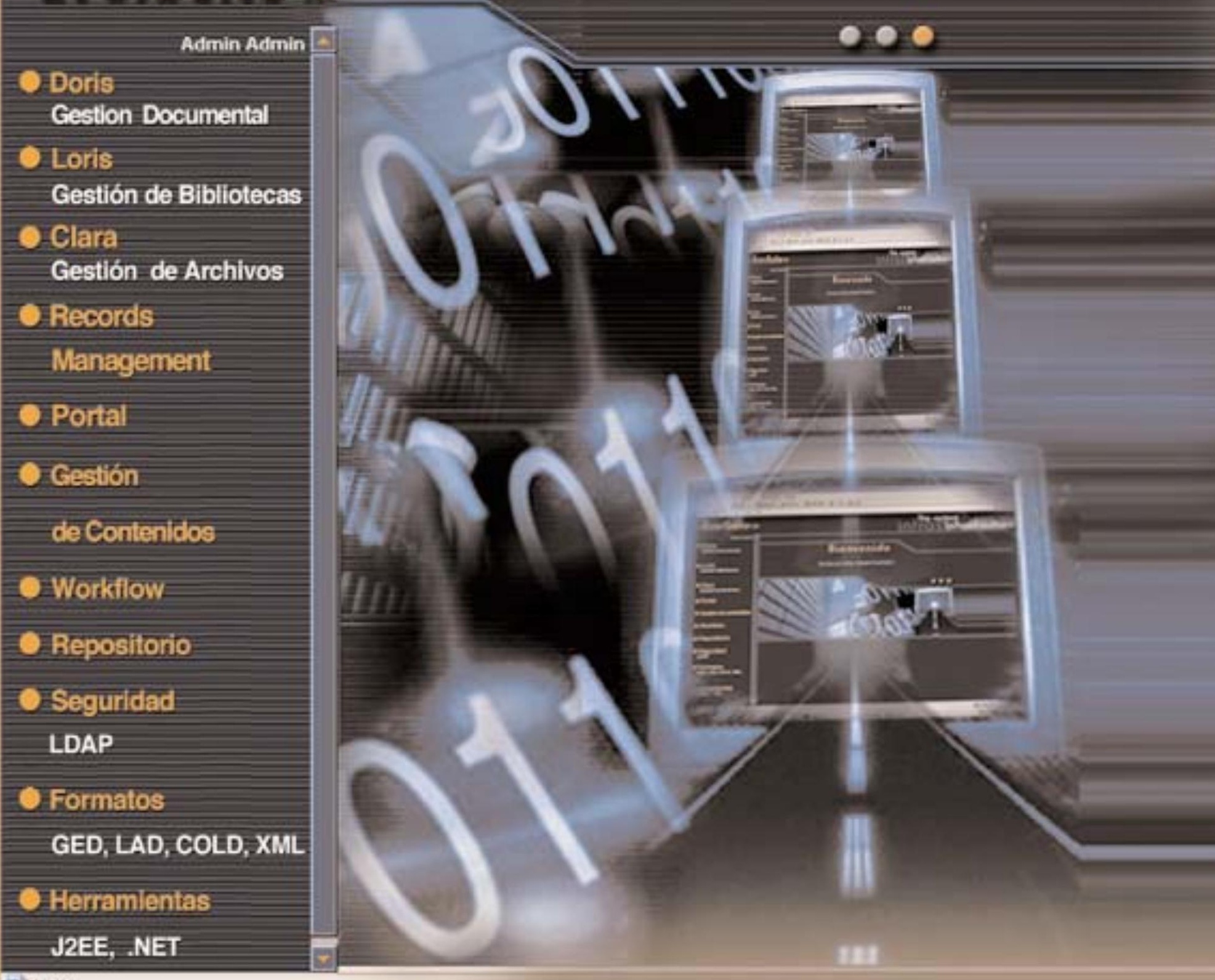

E) Listo

田Inicio $6\left[\begin{array}{ll}0 \\ 0\end{array}\right.$

4

[5] conocimiento in goción woconom MUEVOS TELFFCROS

TEEFONO MA340 the

Fax 374346 ats

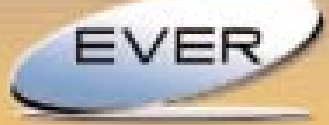

Web: www.everdocumentica,com wrww.ever-team.com

E-mail: ever everdoc.com

Avda,de ia Industria, 32 Edificio Payma

28108 Alcobendas (Madrid)

Telf. 916.630 .258

Fax.916.630.199 
Fokker, D. W. "Requirements for a user-friendly opac". En: The electronic library, 1989, v. 7, n. 1, pp. 4-10.

Frías Montoya, José Antonio. "El opac y el futuro de los puntos de acceso a la descripción”. En: Boletín de la Anabad, 1997, v. 47, n. 1, pp. 78-100.

Frías Montoya, José Antonio. "Implicaciones del opac para la descripción bibliográfica”. En: Boletín de la Anabad, 1996, abril-junio, v. 46, n 2, pp. 47-57.

Frías Montoya, José Antonio. "El opac y el futuro de los puntos de acceso a la descripción: revisión bibliográfica”. En: Boletín de la Anabad, 1997, enero-marzo, v. 47, n. 1, pp. 77-100.

Frías Montoya, José Antonio. "Los registros bibliográficos y las necesidades informativas de los usuarios". En: Scire, 1996, enero-junio, v. 2, n. 1, pp. 23-50.

Frías Montoya, José Antonio. "El control de autoridades y el acceso a la información”. En: Pinto Molina, María (ed.). Catalogación de documentos: teoría y práctica. Madrid: Síntesis, 1994, pp. 436.

Frías Montoya, José Antonio; Ríos Hilario, Ana Belén. “Tendencias actuales en la catalogación: hacia la funcionalidad de los registros bibliográficos". En: Temas de biblioteconomía universitaria y general. Madrid: Editorial Complutense, 2002, pp. 311-343.

Graham, Peter. "Quality in cataloging making distinctions". En: The journal of academic librarianship, 1998, v. 16, n. 4, pp. 213-218.

Goodchild, Andrew. "An overview of catalog design problems in resource discovery". En: Internet research: electronic networking applications and policy, 1996, v. 6, n. 1, pp. 33-43.

Harmsen, B. "Adding value to web-opacs". En: The electronic library, 2000 , v. 18 , n. 2 , pp. $109-113$.

Herrero Pascual, Cristina. "El control de autoridades". En: Anales de documentación, 1999, n. 2, pp. 121-136.

Herrero Solana, Víctor. "La calidad en bases de datos españolas: estudio de la tasa de error en las bases de datos del Csic". En: Revista española de documentación científica, 1997, v. 20, n. 4, pp. 409-416.

Ifla/Fiab. Directrices para las entradas de autoridad y referencia. Traducción de $\mathbf{M}^{\mathbf{a}}$ Dolores del Castillo. Madrid: Arco/Libros, 1993.

Ifla. Guidelines for subject authority and reference entries. Munchen: KG. Saur, 1993. Versión española: Ifla/Fiab. Directrices para los registros de autoridad y referencia de materia. Madrid: Anabad; Arco/libros, 1996.

Jacso, P. "Sarching for skeleyons in the databse cupboard. Part I: errors of ommision". En: Database, 1993, v. 6, n. 1, pp. 67-76

Lombardo, S. V.; Condic, K. S. "Empowering users with a new online catalog". En: Library hi tech, 2000, v. 18, n. 2, pp. 130-141.

Mano González, Marta de la. "Propuesta de un sistema de evaluación para bibliotecas universitarias". En: Revista española de documentación científica, 1998, v. 21, n. 2, pp. 174-197.

Moscoso, Purificación. "Análisis y evaluación de catálogos automatizados de acceso público en entorno web". En: Revista española de documentación científica, 1998, v. 21, n. 1, pp. 57-75.

Moya Anegón, Félix de; López Gijón, Javier; García Caro, Concepción. Técnicas cuantitativas aplicadas a la biblioteconomía y a la documentación. Madrid: Síntesis, 1996.

Moya Anegón, Félix de. Los sistemas integrados de gestión bibliotecaria: estructuras de datos y recuperación de información. Madrid: Anabad, 1995.

Open archives initiative-protocol for metadata harvesting. Consultado en: 30-06-03.

http://www.openarchives.org

Ortego Lorenzo Cáceres, Pilar; Bonal Zazo, José Luis. "Evaluación de calidad de catálogos mediante el uso de tests de suciedad". En: Jornadas bibliotecarias de Andalucía, 2000, pp. 229-236.
Ortego Lorenzo Cáceres, Pilar; Bonal Zazo, José Luis. ’Los problemas de la catalogación cooperativa: propuesta de indicadores de evaluación de catálogos". Consultado en: 18-05-01.

http://www.ubu.es/biblioteca/bucle/4.htm

Ortiz-Repiso Jiménez, Virginia. “QQué enseñamos después del marc?”. En: III Encuentro de Isko-España: organización del conocimiento en sistemas de información y documentación, 1997, pp. 217-225.

Pérez Díez, Amalia Vicenta. Perfil y nivel de satisfacción de los usuarios del opac de una biblioteca universitaria. Madrid: Cindoc; Fesabid, 1996

Pinto Molina, María. "Gestión de calidad en documentación". En: Anales de documentación, 1998, n. 1, pp. 171-183.

Pinto Molina, María. "Indicadores de calidad descriptiva en la gestión de procesos analítico-documentales". En: Jornadas españolas de documentación automatizada, 1994, pp. 189-204.

Pinto Molina, María: "Criterios de calidad total en la biblioteca según el modelo europeo". En: Jornadas bibliotecarias de Andalucía, 1998, pp. 111-126.

Poll, Roswitha; Boekhorst, Peter te. Medición de la calidad: directrices internacionales para la medición del rendimiento en las bibliotecas universitarias. Madrid: Anabad, 1998.

Pujol, D. Claus per a l'èxit: indicadors de rendiment per a biblioteques públiques. Barcelona: Col-legi Oficial de Bibliotecaris-Documentalistes de Catalunya, 1995

Quijano Solís, Álvaro; Ariola Navarrete, Oscar. "Medidas de calidad en al creación de catálogos de bibliotecas". En: Investigación bibliotecológica, 1998, enero-junio, v. 2, n. 24, pp. 49-56.

Ramesh Babu, B.; O'Brien, Ann. "Web opac interfaces: an overview". En: The electronic library, 2000, v. 18, n. 5, pp. 316-327.

Reeb, Richard. "A quantitative meted for evaluating the quality of cataloging”. En: Cataloging and classification quarterly, 1984, winter, v. 5, n. 2, pp. 21-26.

Ríos García, Yolanda. "Opacs: estado de la cuestión". En: Jornada de la Socadi con la colaboración de DOC6, 1991, pp. 7-11.

Ríos García, Yolanda. "Catálogos en línea de acceso público: selección bibliográfica”. En: Revista española de documentación científica, v. 14, n. 2, 1991, pp. 121-141.

Rodríguez Bravo, Blanca; Alvite Díez, Ma Luisa. "Evaluación de interfaces de opacs implementadas con Innopac Millenium". En: Jornadas bibliotecarias de Andalucía, 2002, pp. 399-413.

Rodríguez Yunta, Luis. "Evaluación de calidad en bases de datos". Curso Control de calidad en bases de datos bibliográficas. Madrid, Cindoc, 5-6 mayo 1999.

Thomas, Sarah E. "Quality in bibliographic control". En: Library trends, 1996, winter, v. 44, n. 3, pp. 491-505.

Zapico Alonso, Felipe. "Calidad de encabezamientos en Bibliotecas Publicas del Estado: sus catálogos automatizados y el usuario”. En: Jornadas bibliotecarias de Andalucía, 1998, pp. 139-155.

Zapico Alonso, Felipe. "El sistema de ayuda al usuario de un catálogo en línea de acceso público (opac): delimitación teórica y propuesta práctica". En: Jornadas bibliotecarias de Andalucía, 2002, pp. 415-431.

Zapico Alonso, Felipe. "Problemas de acceso del usuario a la información en entornos globales: los puntos de acceso nominales". En: Jornadas bibliotecarias de Andalucía, 2002, pp. 473-481.

UNE 66-904-90. Gestión de la calidad y elementos de un sistema de calidad. Reglas generales. Madrid: Aenor, 1992, pp. 19.

Wulff Barreiro, E. "Calidad de la indización en bases de datos de tamaños cualesquiera”. En: Boletín de la Asociación Andaluza de Bibliotecarios, 1993, v. 9, n. 31, pp. 41-45.

$M^{a}$ Victoria Játiva Miralles, Universidad de Alicante, Sibid, biblioteca de Filosofía y Letras-Trabajo Social. victoria.jativa@ua.es 